\title{
Solitary Thyroid Nodule: Clinical, Sonography and Pathological Evaluation Risk of Malignancy
}

\author{
Burkan Nasr 1,2,3*, M. Qubati4, S. Qubati5, Abdulhakim Al-Tamimi2 ${ }^{2}$, Yasser A. Rabo6, \\ Anwar Aljounaeed', Abdulfatah Al-Tam7, Mohmmed Al-Shujaa', Mohmmed Al-Shehari ${ }^{3}$
}

\author{
${ }^{1}$ Department of Surgery, Saudi Hospital at Hajjah, Hajjah, Yemen \\ ${ }^{2}$ Department of Surgery, Aden University, Aden, Yemen \\ ${ }^{3}$ Department of Surgery, Sanaà University, Sanaà, Yemen \\ ${ }^{4}$ Department of Pathology, Taiz University, Taiz, Yemen \\ ${ }^{5}$ Department of Pathology, Thamar University, Thamar, Yemen \\ ${ }^{6}$ Department of Surgery, Thamar University, Thamar, Yemen \\ ${ }^{7}$ Department of Surgery, 21 September University, Sanaà, Yemen \\ Email: ^Burkan.nasr2@gmail.com, ^Burkan.naser@yahoo.com
}

How to cite this paper: Burkan, N., Qubati, M., Qubati, S., Al-Tamimi, A., Rabo, Y.A., Aljounaeed, A., Al-Tam, A., Al-Shujaa, M. and Al-Shehari, M. (2021) Solitary Thyroid Nodule: Clinical, Sonography and $\mathrm{Pa}$ thological Evaluation Risk of Malignancy. International Journal of Otolaryngology and Head \& Neck Surgery, 10, 441-476. https://doi.org/10.4236/ijohns.2021.105041

Received: August 14, 2021

Accepted: September 27, 2021

Published: September 30, 2021

Copyright (อ 2021 by author(s) and Scientific Research Publishing Inc. This work is licensed under the Creative Commons Attribution International License (CC BY 4.0).

http://creativecommons.org/licenses/by/4.0/ (c) (i) Open Access

\begin{abstract}
Aim: To determined risk of increases Incidence of Thyroid cancer in solitary thyroid nodules so Preoperative distinction between benign and malignant in solitary thyroid nodules is important and helps to avoid unnecessary surgery and its adverse effects, such as hypothyroidism, hypocalcemia, and recurrent nerve injury. Methods: Descriptive perspective analyzed data over a period of 6 years April 2015-April 2021 in Saudi Hospital at Hajjah, Yemen. 226 thyroid operations for 207 patients, 135 patient's diagnosis as Solitary thyroid nodule and 72 patients as Multi nodular goiter. Patients with a clinically solitary thyroid nodule were included in the study group. Results: 135 cases of clinically detected solitary thyroid nodules, 126 female and 9 male patients, between 14 - 65 years age, median 41 years and mean 39.76 years, $(94,41)$ patients respectively Right side thyroid effect more than Left side, Fine needle aspiration cytology (FNAC) sensitivity, specificity and accuracy was (61\%, $72 \%, 64 \%)$ respectively. Postoperative histopathology reported $100(74 \%)$ patients as having benign thyroid nodules and 35 patients (26\%) as having malignant thyroid nodules. Postoperative transient hypocalcemia was observed in 9 patients (7\%), and temporary hoarseness was observed in 3 patients (2\%). Conclusion: The incidence of malignancy in solitary thyroid nodules is high. Rapid growth by history and hard fixed nodule by examination and hypoechoic, micro calcification and cervical lymphadenopathy on Thyroid Ultrasound frequently in malignant nodules. Male risk factors for thyroid cancer but age, number and size of nodules not included as risk factor. Fine needle aspiration cytology (FNAC) is more helpful for diagnosing if aspiration under
\end{abstract}


Ultrasound guidance and reading by experience histopathologists. The type of surgery depends on preoperative evaluation, including history, examination, ultrasound, fine needle aspiration cytology (FNAC) result, and intraoperative assessment of the nodule. There are fewer complications of thyroid surgery by experienced surgeons.

\section{Keywords}

Solitary Thyroid Nodule, Thyroid Cancer, Fine Needle Aspiration Cytology, Thyroid Ultrasound

\section{Introduction}

Solitary thyroid nodules are defined clinically as localized thyroid enlargement with an apparently normal remaining gland and refer to abnormal growth of thyroid cells that forms a lump within the thyroid gland. Although the vast majority of thyroid nodules are benign, a small proportion of thyroid nodules contain thyroid cancer. To diagnose and treat thyroid cancer at the earliest stage, most thyroid nodules need some type of evaluation. Often, these abnormal growths of thyroid tissue are located at the edge of the thyroid gland, so they can be felt as a lump in front of the neck. When they are large or when they occur in very thin individuals, they can sometimes even be seen as a lump in front of the neck [1]. Thyroid nodules are common. The prevalence and incidence increase with age, with spontaneous nodules occurring at a rate of $0.08 \%$ per year beginning early in life and extending into the eighth decade. Palpable thyroid nodules are found in $5 \%$ of persons aged an average of 60 years. With the use of imaging techniques, particularly ultrasound, the chance of detection of thyroid nodules has increased many-fold, approximately $20 \%$ - 60\% [2]-[7].

Thyroid nodules are more common in women than in men, its incidence in females is approximately one in 12 - 15 young women who have a thyroid nodule, but in males, it is approximately one in 40 young men who have a thyroid nodule. More than $95 \%$ of all thyroid nodules are benign (noncancerous growths) [3] [4] [5].

However, the reported incidence of thyroid cancer in the general population is low, at only approximately $1 \%$. Thyroid cancers occur in approximately $5 \%-$ $15 \%$ of all thyroid nodules independent of their size [3] [8].

Recent data suggest that the incidence of thyroid malignancy has increased over the years [2] [3]. The worldwide increase in the incidence of thyroid cancer is partly due to increased detection by US and other imaging studies but also to a true increase in the incidence of papillary thyroid carcinoma (PTC) [9].

The occurrence of malignancy is more common in solitary thyroid nodules (STNs) than in multinodular goiters [2] [10] [11].

The preoperative evaluation of thyroid nodules to distinguish between benign and malignant nodules is very important. It helps to avoid unnecessary extensive 
surgery and potential surgery-related adverse effects, such as hypothyroidism, hypocalcemia, and recurrent laryngeal nerve injury [2].

Preoperative diagnoses were classified as benign, suspicious or malignant based on history, clinical examination findings (i.e. cervical lymphadenopathy, hoarseness of voice, presence of metastasis), thyroid function test, ultrasonographic features and FNAC (The Bethesda system for reporting thyroid cytopathology) [12] [13].

Ultrasound of the thyroid gland is used to differentiate true solitary thyroid nodules from those with multinodular glands. Additionally, it classifies the nodule into solid, cystic, or mixed. However, it provides little help in determining the pathological types of the nodule [14].

Fine-needle aspiration (FNA) cytology is the first step that is performed to differentiate malignant nodules; however, $5 \%$ - 15\% of FNA revealed inadequate nondiagnostic samples, and $15 \%$ - 30\% of FNA results in indeterminate cytology findings category III (atypia or follicular neoplasm of undetermined significance) and category IV (suspicious for follicular neoplasm) according to the Bethesda system [15] [16].

Fine-needle aspiration cytology (FNA) is regarded as the first diagnostic step to differentiate malignant from benign nodules. FNA has served with high accuracy to diagnose papillary thyroid carcinoma, which accounts for $80 \%-90 \%$ of all thyroid cancers because papillary thyroid carcinoma has several specific cytological nuclear features, such as optically clear elongated nuclei with nuclear grooves and intranuclear cytoplasmic pseudo inclusions [17] [18] [19].

Fine-needle aspiration cytology (FNAC) has become the cornerstone investigation. Unfortunately, on the basis of cytological characteristics alone, pathologists cannot reliably distinguish benign from malignant follicular thyroid lesions, $\sim 20 \%$ of fine-needle aspiration cytology (FNAC) will be given a final diagnosis of follicular malignancy [20].

For benign solitary nodules, hemithyroidectomy of the involved lobe is recommended, not total thyroidectomy, but in treating suspicious and false-negative (FN) cases, fine-needle aspiration cytology (FNAC) reports could be overcome by total thyroidectomy. Hemithyroidectomy with or without isthmusectomy is performed as the initial operation for patients with an indeterminate cytological diagnosis and no clinical evidence of regional or distant metastatic disease or any other concurrent indication for total thyroidectomy. If gross extrathyroidal tumor extension or lymph node metastasis is found at the time of operation, a total thyroidectomy is then carried out [21].

The aim of the present study was to evaluate patients with clinically detected solitary thyroid nodules for the presence of malignancy in relation to various factors, such as age, gender family history, rapid growth and hard clinical examination, fixed nodules and ultrasonography (USG) findings, such as the size of the nodule, echogenicity, microcalcification, and presence of lymphadenopathy, as well as fine-needle aspiration cytology (FNAC) results. We also planned 
to compare the prevalence of malignancy in both solitary and multiple thyroid nodules detected by ultrasonography (USG).

\section{Materials and Methods}

This is a descriptive perspective analyzed our departmental data over a period of 6 years April 2015-April 2021. By single team surgeon, in Saudi hospital at Hajjah, Yemen. Approximately 226 thyroid operations were performed for 207 patients; 72 patients were diagnosed before operation with multinodular goiters ware excluded from this study and 135 patients were diagnosed clinically with solitary thyroid nodules and underwent surgery in our surgical department were included in the study group. Preoperative history, examination, thyroid function test, ultrasonography (USG) and fine-needle aspiration cytology were planned in all these patients. Hemithyroidectomy and total thyroidectomy with and without neck dissection were performed wherever appropriate. The patients and their relatives gave inform consent to use the information for publication purposes. The study was approved by the institutional ethics committee.

For all patients, the following data were recorded: age, sex, history of radiation exposure, family history of thyroid disease, symptoms and growth rate of nodules, and thyroid hormone profile. The operative procedure was based on different parameters, such as the age of the patients, clinical examination, ultrasound interpretation, fine-needle aspiration cytology (FNAC) findings and indirect laryngoscopy. The decision for surgery was based on individual patient examination and investigation findings.

In most of the patients, the plan of surgery was decided beforehand. If it was a solitary thyroid nodule diagnosed clinically, ultrasonographic and fine-needle aspiration cytology (FNAC) as malignancy or high suspicion for malignancy proceeded with total thyroidectomy. For others, lower grade hemithyroidectomy of the involved side was performed, and the specimen was sent for routine histopathological examination (HPE). Because of inconclusive results and the lack of frozen section use, we preferred to wait until the final histopathology report. If the histopathological result was positive for malignancy, completion thyroidectomy was performed in 4 - 6 weeks. The decision for other procedures, total thyroidectomy with central neck dissection, total thyroidectomy with selective neck dissection, and total thyroidectomy with modified radical neck dissection, was based on clinical, radiological, fine-needle aspiration cytology (FNAC) and histopathology findings.

During surgery, the site and type of incision were decided. Hemostasis, safeguarding of the recurrent laryngeal nerve, parathyroid, and other vital structures, was taken care of during the dissection. Appropriate measures were taken to correct postoperative hypocalcemia, and care of the drain was taken. Further treatment plans were decided based on the final histopathology report. If the report was benign, the patient was managed by regular monitoring of hormone levels, with or without thyroid hormone supplementation. Hypocalcemia fea- 
tures were managed with supplementation with calcium and vitamin D.

If the final histopathology report was either follicular or papillary carcinoma, the patients were advised to undergo an I-131 whole body scan, preferably within 4 - 6 weeks after surgery, and radioactive iodine ablation was advised for residual tissue in the thyroid bed. All the patients were advised regular follow-up for one week, one month, 6 months, one year, and 2 years.

Statistical analysis was performed using Statistical Packages for Social Sciences (SPSS), version 20.0 software (SPSS Inc; Chicago, IL, USA). Comparison of proportions between groups was performed by the $\chi^{2}$ test, taking $P<0.05$ as significant.

\section{Results}

During our study period from April 2015-April 2021 in the Surgical Department of Saudi Hospital at Hajjah Yemen, approximately 226 thyroid operations were performed for 207 patients, 72 (35\%) patients were diagnosed with multinodular goiters ware excluded from our study and 135 (65\%) patients were diagnosed clinically with solitary thyroid nodules were included in our study.

135 patients were diagnosed clinical as Solitary thyroid nodule underwent for 154 thyroid operations. (Table 1, Figure 1 and Table 2) show the sociodemographic data by sex and age, incidence Solitary thyroid nodule according to the Sex to $126 / 135$ (93\%) female and $9 / 135$ (7\%) male. There were 135 patients with solitary thyroid nodule b/n age 14 - 65 years, median age 41 years, mode 45 years, average mean age 39.76 years, ring 51 years and Stander deviation 13.98.

Table 1 . Solitary thyroid nodule according to the sex.

\begin{tabular}{ccccccc}
\hline Sex & $\begin{array}{c}\text { Total } \\
(\mathrm{N}=135)\end{array}$ & $\%$ & $\begin{array}{c}\text { Benign } \\
(\mathrm{N}=100)\end{array}$ & $\%$ & $\begin{array}{c}\text { Malignant } \\
(\mathrm{N}=35)\end{array}$ & $\%$ \\
\hline Female & 126 & $93 \%$ & 95 & $95 \%$ & 31 & $89 \%$ \\
Male & 9 & $7 \%$ & 5 & $5 \%$ & 4 & $11 \%$ \\
Total & 135 & $100 \%$ & 100 & $100 \%$ & 35 & $100 \%$ \\
\hline
\end{tabular}

Table 2. Solitary thyroid nodule according to the age group.

\begin{tabular}{|c|c|c|c|c|c|c|}
\hline Age group & $\begin{array}{c}\text { Total } \\
(\mathrm{N}=135)\end{array}$ & $\%$ & $\begin{array}{c}\text { Benign } \\
(\mathrm{N}=100)\end{array}$ & $\%$ & $\begin{array}{c}\text { Malignant } \\
(\mathrm{N}=35)\end{array}$ & $\%$ \\
\hline$<20$ & 13 & $10 \%$ & 11 & $11 \%$ & 2 & $6 \%$ \\
\hline $21-30$ & 50 & $37 \%$ & 38 & $38 \%$ & 12 & $34 \%$ \\
\hline $31-40$ & 25 & $19 \%$ & 17 & $17 \%$ & 8 & $23 \%$ \\
\hline $41-50$ & 29 & $21 \%$ & 21 & $21 \%$ & 8 & $23 \%$ \\
\hline $51-60$ & 16 & $12 \%$ & 12 & $12 \%$ & 4 & $11 \%$ \\
\hline$>60$ & 2 & $1 \%$ & 1 & $1 \%$ & 1 & $3 \%$ \\
\hline Total & 135 & & 100 & & 35 & \\
\hline
\end{tabular}




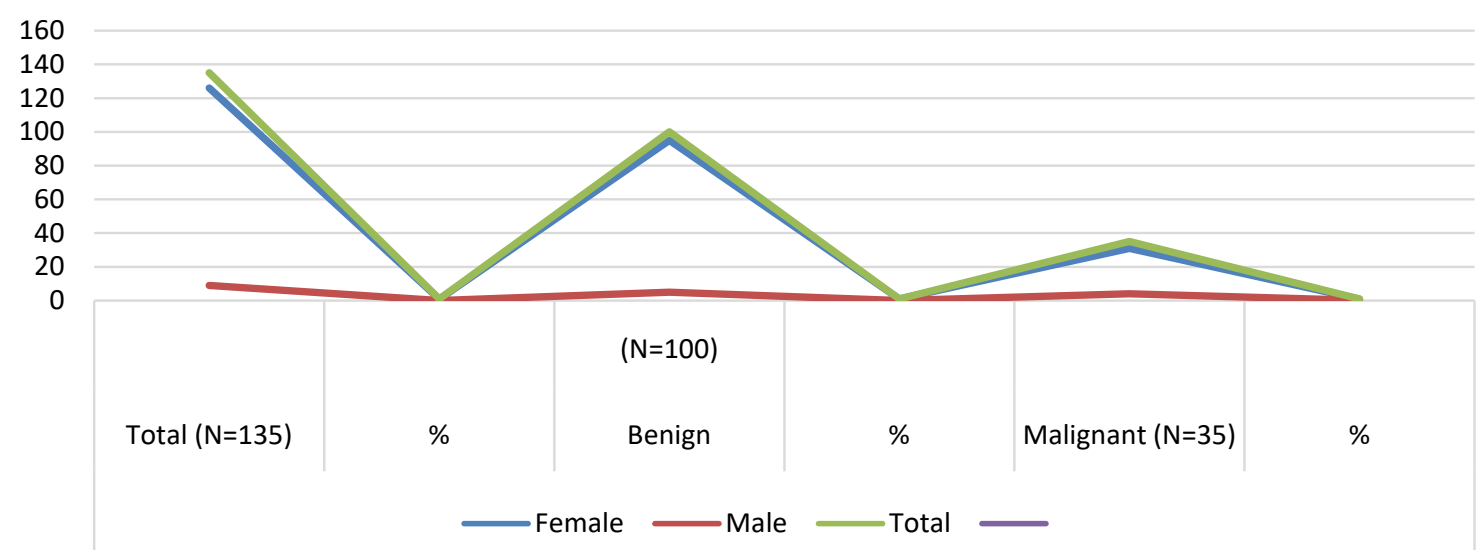

Figure 1. Solitary thyroid nodules according to the sex.

The histopathology results showed that 100/135 patients (74\%) developed benign thyroid nodules from patients diagnosed clinically with solitary thyroid nodules. 95/135 was female (70\%) and 5/135 male (4\%), 95/100 was female (95\%) and 5/100 was male (5\%).

All patients were diagnosed clinically with solitary thyroid nodules. Histopathology showed benign thyroid nodules at age b/n 14 - 65 years, median age 31.5 years, mode 30 years, average mean age 34.72 years and standard deviation 12.40.

The histopathology results showed that $35 / 135$ patients (26\%) developed thyroid cancer from patients diagnosed clinically with solitary thyroid nodules. A total of $31 / 135$ was female (23\%), 4/135 were male (3\%), 31/35 were female (89\%), and $4 / 35$ were male (11\%).

The incidence of thyroid cancer in females with solitary thyroid nodules was $31 / 126(25 \%)$.

The incidence of thyroid cancer in males with solitary thyroid nodules was $4 / 9$ (44.44\%). This indicates a high incidence of thyroid cancer in male patients.

Solitary thyroid nodule more Common in age group between 21 - 30 years old are about 50 patients and the next age group between $41-50$ years old are about 29 patients. But the patients with Histopathology showed thyroid cancer with average age range b/n 15 - 62 years, median age 35 years, mode 23 years, average mean age 35.97 years, and standard deviation 11.91 .

Table 3 and Figure 2 show distribution according to the side that 135 Patients with Solitary Thyroid Nodule There is 94 Patients Rt Side Solitary Thyroid Nodule and 41 Patients Lt Side Solitary Thyroid Nodule, Our result, Solitary thyroid nodule appear (70\%) in Rt Side of thyroid and (30\%) in Lt Side of thyroid that indicated Rt side effects more than Lt side thyroid.

Benign solitary thyroid nodule distribute according to side as following Rt side 72/100 (72\%), and Lt side 28/100 (28\%), Rt side benign solitary thyroid nodule appear in 72 patients 69 female and 3 male patients, clinical diagnosis as Rt side true Solitary thyroid nodule 49 patients, cystic Rt side solitary thyroid nodule 7 patients, 13 patients prominent Rt side solitary thyroid nodule and 3 patients Rt side solitary thyroid nodule Toxic adenoma. 


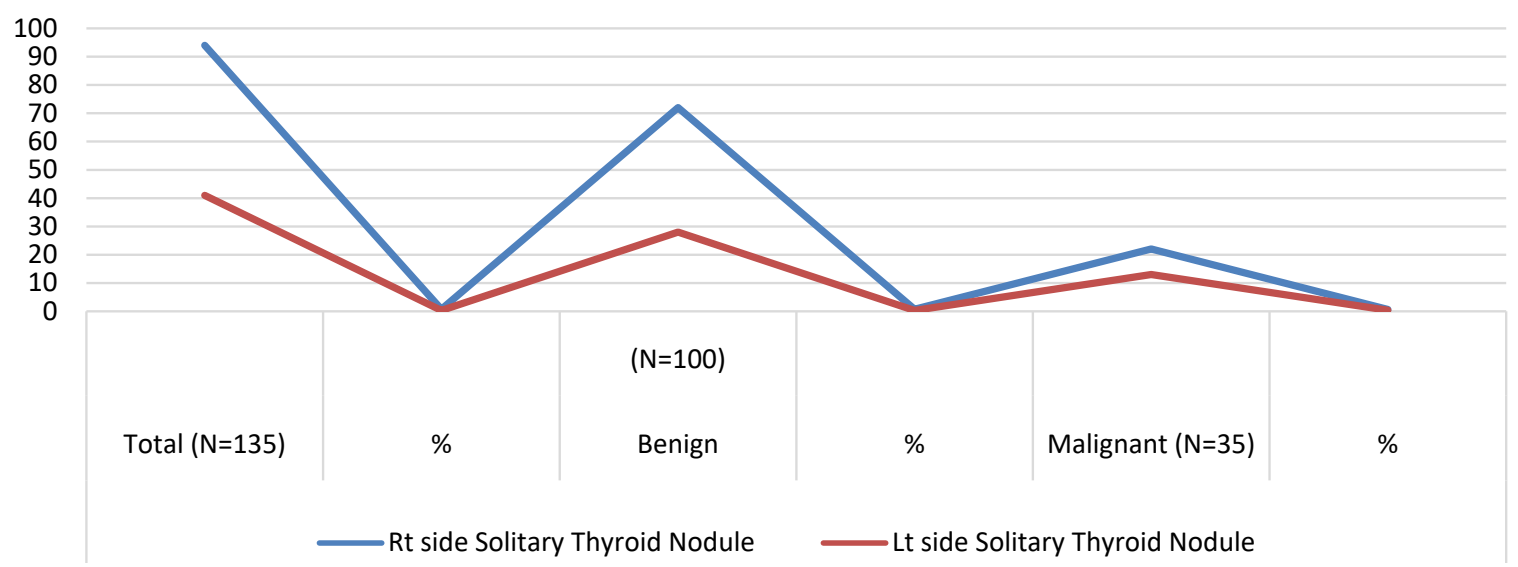

Figure 2. Solitary thyroid nodule according to side.

Table 3. Solitary thyroid nodule according to side.

\begin{tabular}{ccccccc}
\hline Side & $\begin{array}{c}\text { Total } \\
(\mathrm{N}=135)\end{array}$ & $\%$ & $\begin{array}{c}\text { Benign } \\
(\mathrm{N}=100)\end{array}$ & $\begin{array}{c}\text { Malignant } \\
(\mathrm{N}=35)\end{array}$ & $\%$ \\
\hline Rt side Solitary Thyroid Nodule & 94 & $70 \%$ & 72 & $72 \%$ & 22 & $63 \%$ \\
Lt side Solitary Thyroid Nodule & 41 & $30 \%$ & 28 & $28 \%$ & 13 & $37 \%$ \\
\hline
\end{tabular}

Lt side benign solitary thyroid nodule appear 28 patients 26 female and 2 male patients, clinical diagnosis as Lt side true Solitary thyroid nodule 17 patients, 2 patients with huge nodule $7-8 \mathrm{~cm}$, cystic Lt solitary thyroid nodule 3 patients, prominent Lt Solitary thyroid nodule in 7 patients.

Solitary thyroid malignant nodules appeared more frequently at Rt Side Thyroid in $22 / 35$ patients $(63 \%)$ and $13 / 35$ patients (37\%) at Lt Side of the thyroid gland.

135 patients with solitary thyroid nodule distribute according to size of nodule by $\mathrm{cm}$, Most Solitary thyroid nodule even benign or malignant nodule take size between $2.1-4 \mathrm{~cm}, 67 / 135$ (50\%) Patients with Solitary thyroid nodule show size of nodule b/n $2.1-4 \mathrm{~cm}, 50 / 100$ patients (50\%) with benign Solitary thyroid nodule show size of nodule between $2.1-4 \mathrm{~cm}$ and 17/35 (49\%) Patients with Malignant Solitary Thyroid was Size b/n $2.1-4 \mathrm{~cm}$ mostly effected groups (Table 4, Figure 3).

Before the operation history and clinical examination were performed for all patients, the most common presentation of STN was swelling in the anterior aspect of the neck. Swelling was noticed by the patient's relatives in most instances and, in a few cases, by the patients themselves. Other less common symptoms were pain, hoarseness and dysphagia. The duration of symptoms ranged from one to 24 months. Rapid growth of nodules lasted significantly last 3 - 6 months in 20 cases, family history of thyroid nodules was positive in 10 cases, and hard nodules were positive in 32 cases.

Laboratory tests, including thyroid function tests, showed (Table 5, Figure 4), thyroid function tests were performed in all 135 patients. A total of 125 (93\%) patients were euthyroid, 6 (4\%) were hypothyroid, and 4 (3\%) were hyperthyroid. 
Table 4. Solitary thyroid nodule according to size of nodule (CM).

\begin{tabular}{ccccccc}
\hline Size & Total $(\mathrm{N}=135)$ & $\%$ & $\begin{array}{c}\text { Benign } \\
(\mathrm{N}=100)\end{array}$ & $\%$ & $\begin{array}{c}\text { Malignant } \\
(\mathrm{N}=35)\end{array}$ & $\%$ \\
\hline$<1$ & 5 & $4 \%$ & 1 & $1 \%$ & 4 & $11 \%$ \\
$1.0-2.0$ & 29 & $21 \%$ & 22 & $22 \%$ & 7 & $20 \%$ \\
$2.1-4.0$ & 67 & $50 \%$ & 50 & $50 \%$ & 17 & $49 \%$ \\
$>4.0$ & 34 & $25 \%$ & 27 & $27 \%$ & 7 & $20 \%$ \\
\hline
\end{tabular}

Table 5. Solitary thyroid nodule according to the function.

\begin{tabular}{ccccccc}
\hline Thyroid function & $\begin{array}{c}\text { Total } \\
(\mathbf{N}=135)\end{array}$ & $\%$ & $\begin{array}{c}\text { Benign } \\
(\mathbf{N}=100)\end{array}$ & $\%$ & $\begin{array}{c}\text { Malignant } \\
(\mathbf{N}=35)\end{array}$ & $\%$ \\
\hline Euthyroid & 125 & $93 \%$ & 93 & $93 \%$ & 32 & $91 \%$ \\
Hyperthyroidism & 4 & $3 \%$ & 4 & $4 \%$ & 0 & $0 \%$ \\
Hypothyroidism & 6 & $4 \%$ & 3 & $3 \%$ & 3 & $9 \%$ \\
\hline
\end{tabular}

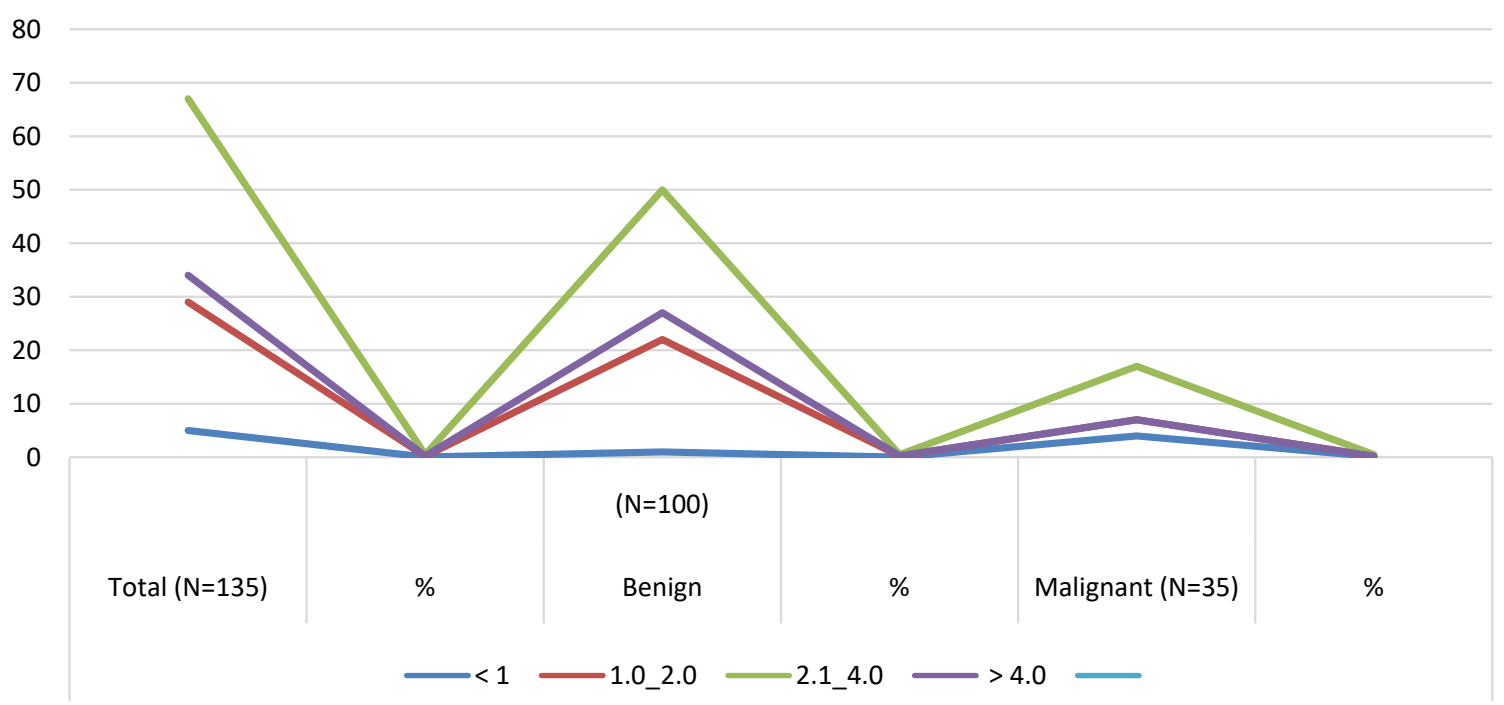

Figure 3. Solitary thyroid Nodules according to size $(\mathrm{cm})$.

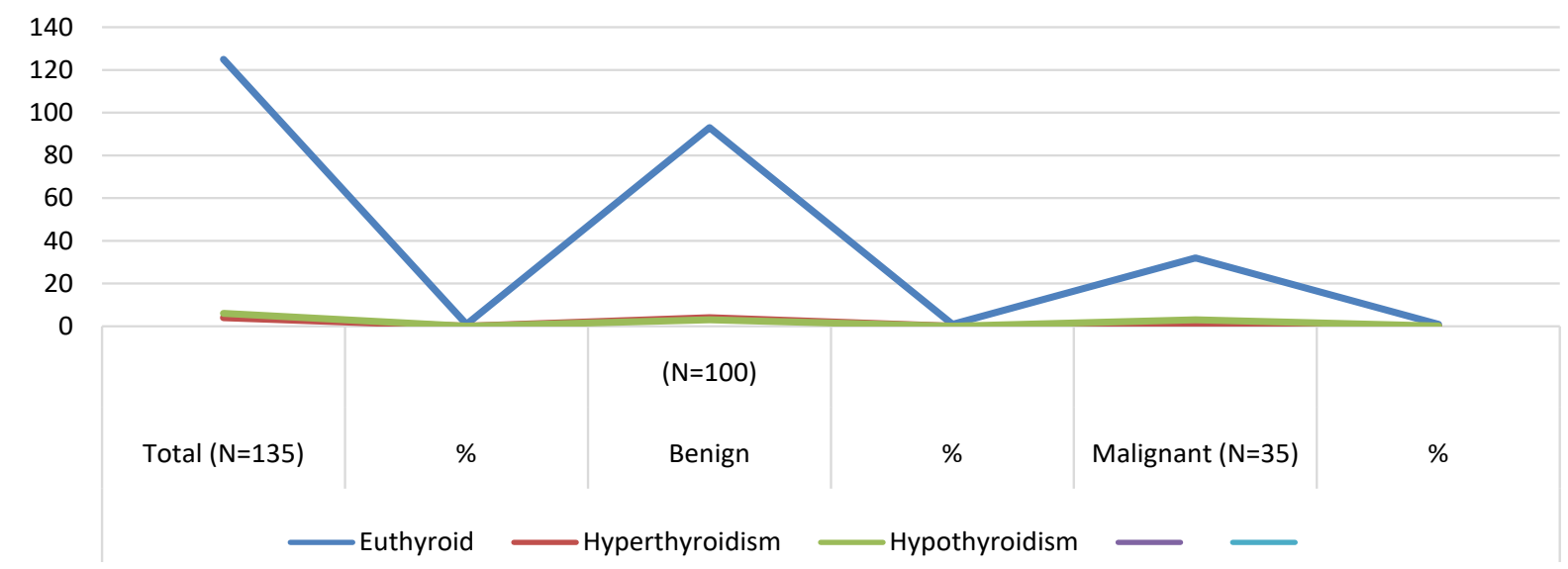

Figure 4. Solitary thyroid nodule according to function. 
Before surgery, these patients were euthyroid by supplementing thyroxin or by treatment with antithyroid drugs.

Benign STN According to the functional euthyroid appear clinical and para clinical before surgery in 93/100 (93\%) patients with Benign solitary thyroid nodule, 32/35 (91\%) patients with malignant solitary thyroid nodule.

Hypothyroidism occurred in 5 females and one male, hypothyroidism occurred in 4 patients with Rt solitary thyroid nodules, and 2 patients had Lt solitary thyroid nodules.

By FNAC 2 cases with Benign colloid nodule with compression symptoms, one case follicular neoplasia, one case Hurthle cell neoplasia, one case suspicious categories, one case papillary thyroid cancer. Benign solitary thyroid nodules appeared in 3/6 (50\%) patients, with hypothyroidism. All patients were female, 2 on the Lt side and one on the Rt side. The results of histopathology were Hashimotos thyroiditis in 2 cases and one case of colloid goiter with a hyperplastic nodule. After becoming euthyroid by medical treatment, surgery was performed by total thyroidectomy in 2 cases and Rt hemithyroidectomy in one case.

Malignant solitary thyroid nodules appeared in 3/6 (50\%) patients with hypothyroidism before the operation. The histopathology results showed malignant nodules such as papillary thyroid cancer on a background of Hashimoto's thyroiditis, one of whom had lymph node metastasis. This means a higher risk for malignant transformation, especially papillary thyroid cancer, than lymphoma after becoming euthyroid by hormonal replacement and undergoing thyroid surgery.

Total thyroidectomy with central lymph node dissection in one patient and total thyroidectomy with Rt lymph node dissection in one patient were complicated by temporary horsnese due to laryngeal edema that improved during the first month.

Rt hemithyroidectomy followed by completion Lt hemithyroidectomy with central lymph node dissection was performed in one patient. It should be noted that all patients received postoperative thyroid hormone replacement, and it should also be noted that not all cases of hypothyroidism were Hashimoto's thyroiditis, as one case of hypothyroidism and histopathology result was colloid goiter with a hyperplastic nodule.

Hyperthyroidism appeared in 4/100 patients. All females had benign solitary thyroid nodules on the Rt side. Histopathology results were benign toxic adenomas in 3 cases and colloid goiter hyperplastic nodules in one case. After becoming euthyroid by medical treatment, the patient underwent surgery by total thyroidectomy, subtotal thyroidectomy, near total thyroidectomy and one case of Rt hemithyroidectomy. Post-hemithyroidectomy was euthyroid follow-up for 5 years, with no recurrence until now, and no patients received any replacement, but all other 3 patients received thyroid hormone therapy.

\subsection{Findings on Ultrasonography and Ultrasonography Predictors of Malignancy}

Neck ultrasound showed solitary thyroid nodules in 135 patients: 85 patients 
(62.96\%) had true solitary nodules, 4 had large nodules with compression symptoms and tracheal deviation, 32 had prominent nodules (23.70\%), 11 had recurrent cystic nodules $(8.14 \%)$, and two $(1.48 \%)$ had apparent thyroid nodules as supraclavicular masses. One patient $(0.7 \%)$ had recurrent Rt solitary thyroid nodules 15 years ago after thyroidectomy, and 4 (2.96\%) patients had Rt side toxic adenomas.

Ultrasound examination findings (Table 6) were available in 135 clinically detected solitary thyroid nodules. Clinical diagnosis of solitary thyroid nodules was confirmed on ultrasound in $85(63 \%)$ patients, whereas in 32 (24\%) patients, ultrasound revealed a prominent nodule of multinodular goiter.

Postoperative histopathology was available for 135 patients, and 35 nodules were reported as malignant. Twenty-three (66\%) true solitary thyroid nodules turned malignant on postoperative histopathology, while 12 patients $(34 \%)$ had prominent nodules of multinodular goiter.

The majority of the nodules $(\mathrm{n}=67,50 \%)$ were $2-4 \mathrm{~cm}$ in size. However, there was no significant correlation between tumor size and the risk of malignancy.

Ultrasound revealed hypoechoic nodules in 33/35 (94\%) patients with malignant nodules and $15(15 \%)$ with benign nodules.

Ultrasound nodules were solid in 30/35 (86\%) patients with malignant nodules, cystic nodules in one patient (3\%) with malignant nodules, and both solid and cystic nodules (mixed echoic) in 4 (11\%) patients with malignant nodules. was solid in $10(10 \%)$ patients with benign nodules, cystic nodules in $10(10 \%)$ patients were benign nodules, and mixed solid and cystic components appeared in $80(80 \%)$ patients with benign nodules.

In addition, ultrasound detected microcalcifications in 38 patients, of whom 28 were malignant and 10 nodules with microcalcifications were benign. Thus, 28 out of a total $35(80 \%)$ malignant cases had microcalcifications, in contrast to 10 of 100 (10\%) benign nodules. Lymph nodal enlargement was detected by

Table 6. Solitary thyroid nodule ultrasound findings.

\begin{tabular}{ccccc}
\hline Ultrasound findings & Benign $(\mathrm{N}=100)$ & $\%$ & Malignant $(\mathrm{N}=35)$ & $\%$ \\
\hline Hypoechoic & 15 & $15 \%$ & 33 & $94 \%$ \\
Lymphadenopathy & 2 & $2 \%$ & 24 & $69 \%$ \\
Calcification & 10 & $10 \%$ & 28 & $80 \%$ \\
Solid & 10 & $10 \%$ & 30 & $86 \%$ \\
Cystic & 10 & $10 \%$ & 1 & $3 \%$ \\
Mixed & 79 & $79 \%$ & 5 & $11 \%$ \\
$<1$ & 1 & $1 \%$ & 4 & $11 \%$ \\
$\mathbf{1 . 0}-\mathbf{2 . 0}$ & 22 & $22 \%$ & 7 & $20 \%$ \\
$\mathbf{2 . 1}-\mathbf{4 . 0}$ & 50 & $50 \%$ & 17 & $49 \%$ \\
$>\mathbf{4 . 0}$ & 27 & $27 \%$ & 7 & $20 \%$ \\
\hline
\end{tabular}


ultrasound in 26 patients. Twenty-four of 35 (69\%) malignant nodules had lymph node enlargement compared with only 2 of 100 (2\%) benign nodules.

\subsection{Fine-Needle Aspiration Cytology}

Fine-needle aspiration cytology results according to the Bethesda Categories (Table 7) were performed before the surgery in all 135 patients and were reported as category $1=6(4 \%)$, category $2=66(50 \%)$, category $3=10(7 \%)$, category $4=39(29 \%)$, category $5=11(8 \%)$, and category $6=3(2 \%)$.

In Table 8, fine needle aspiration cytology results according to the Bethesda categories with its subtypes. As inadequate for diagnosis $6(4 \%)$ patients, colloid

Table 7. Fine needle aspiration cytology results according to the Bethesda Categories.

\begin{tabular}{lcc}
\hline \multicolumn{1}{c}{ Preoperative FNAC results Bethesda Categories } & Number of patients (N = 135) & $\%$ \\
\hline Category 1 Inadequate for diagnosis, unsatisfactory & 6 & $4 \%$ \\
Category 2 Benign cytology & 66 & $50 \%$ \\
Category 3 AUS/FLUS & 10 & $7 \%$ \\
Category 4 FN/SFN & 39 & $29 \%$ \\
Category 5 Suspicious for Malignancy & 11 & $8 \%$ \\
Category 6 Malignant & 3 & $2 \%$ \\
\hline
\end{tabular}

FNAC: Fine needle aspiration cytology, AUS/FLUS: Atypia undetermined significance (AUS) or Follicular lesion of undetermined significance (FLUS), FN/SFN: Follicular neoplasia (FN) or Suspicious Follicular neoplasia (SFN).

Table 8. Fine needle aspiration cytology results according to the Bethesda Categories with its subtypes.

\begin{tabular}{lllc}
\hline \multicolumn{1}{c}{$\begin{array}{c}\text { Preoperative FNAC } \\
\text { Bethesda Categories }\end{array}$} & \multicolumn{1}{c}{ Subtypes } & $\begin{array}{c}\text { Number of } \\
\text { patients N =135 }\end{array}$ & $\%$ \\
\hline $\begin{array}{l}\text { Category 1 Inadequate for } \\
\text { diagnosis }\end{array}$ & Inadequate for diagnosis, unsatisfactory. & 6 & $4 \%$ \\
\hline & Colloid Nodule benign cytology & 28 & $21 \%$ \\
& Adenomatous nodule & 13 & $10 \%$ \\
Category 2 Benign cytology & $\begin{array}{l}\text { Hyperplastic benign nodule } \\
\text { Colloid Cystic nodule }\end{array}$ & 15 & $12 \%$ \\
\hline Category 3 AUS/FLUS & Atypical cells & 7 & $5 \%$ \\
\hline Category 4 FN/SFN & Follicular cell neoplasia & 3 & $2 \%$ \\
\hline Category 5 Suspicious for & Hurthle cell neoplasia & 10 & $7 \%$ \\
\hline Malignancy & Suspicious & 36 & $27 \%$ \\
\hline Category 6 Malignant & Malignant & 3 & $2 \%$ \\
\hline
\end{tabular}

FNAC: Fine needle aspiration cytology, AUS/FLUS: Atypia undetermined significance (AUS) or Follicular lesion of undetermined significance (FLUS), FN/SFN: Follicular neoplasia (FN) or Suspicious Follicular neoplasia (SFN). 
nodule $28(21 \%)$, adenomatous nodule $13(10 \%)$, hyperplastic nodule $15(12 \%)$, colloid cystic nodule 7 (5\%), atypical cell 10 (7\%), follicular cell neoplasia 36 (27\%), Hurthle cell neoplasia $3(2 \%)$, suspicious for malignant $11(8 \%)$, malignant $3(2 \%)$.

Correlations between FNAC and histopathology results (Table 9 and Table $10)$.

Table 9. Matching between Bethesda categories and histological types used to determine FNAC accuracy.

\begin{tabular}{lccc}
\hline Histological types Bethesda Categories & $\begin{array}{c}\text { Benign and } \\
\text { non-neoplastic }\end{array}$ & $\begin{array}{c}\text { Benign and } \\
\text { neoplastic }\end{array}$ & Malignant \\
\hline Category1, 2 Benign cytology & TN & FN & FN \\
Category 3 AUS/FLUS & FP & TP & TP \\
Category 4 FN/SFN & FP & TP & TP \\
Category 5 Suspicious for Malignancy & FP & TP & TP \\
Category 6 Malignant & FP & TP & TP \\
\hline
\end{tabular}

FNAC: Fine needle aspiration cytology, AUS/FLUS: Atypia undetermined significance (AUS) or Follicular lesion of undetermined significance (FLUS), FN/SFN: Follicular neoplasia (FN) or Suspicious Follicular neoplasia (SFN), TN: True negative, TP: True positive, FN: False negative, FP: False positive.

Table 10. Correlation between FNAC and histological diagnoses together with the risk of malignancy calculated for each Bethesda category.

\begin{tabular}{|c|c|c|c|c|}
\hline Bethesda Category & Histopathology subtype & $\begin{array}{l}\text { Number } \\
\text { of cases }\end{array}$ & $\begin{array}{c}\text { True/False } \\
\text { diagnosis }\end{array}$ & $\begin{array}{c}\text { Risk of } \\
\text { malignancy \% }\end{array}$ \\
\hline \multirow{5}{*}{$\begin{array}{c}\text { Category } 1 \\
\text { Inadequate for } \\
\text { diagnosis, } \\
\text { unsatisfactory }\end{array}$} & Hyperplastic nodule & 2 & $\mathrm{TN}$ & \multirow{5}{*}{$17 \%$} \\
\hline & Cystic nodule & 1 & $\mathrm{TN}$ & \\
\hline & Follicular adenoma & 1 & $\mathrm{FN}$ & \\
\hline & Hurthle adenoma & 1 & $\mathrm{FN}$ & \\
\hline & Anaplastic cancer & 1 & $\mathrm{FN}$ & \\
\hline \multirow{11}{*}{$\begin{array}{c}\text { Category } 2 \\
\text { Benign cytology }\end{array}$} & Colloid Nodule & 15 & $\mathrm{TN}$ & \multirow{11}{*}{$17 \%$} \\
\hline & Adenomatous nodule & 11 & $\mathrm{TN}$ & \\
\hline & Hyperplastic nodule & 7 & $\mathrm{TN}$ & \\
\hline & Cystic nodule & 3 & $\mathrm{TN}$ & \\
\hline & Toxic adenoma & 2 & $\mathrm{TN}$ & \\
\hline & Hashimoto's thyroiditis & 2 & $\mathrm{TN}$ & \\
\hline & Follicular adenoma & 11 & FN & \\
\hline & Hurthle adenoma & 1 & FN & \\
\hline & Papillary cancer & 10 & $\mathrm{FN}$ & \\
\hline & Medullary cancer & 1 & $\mathrm{FN}$ & \\
\hline & NIFTP & 3 & FN & \\
\hline
\end{tabular}




\section{Continued}

\begin{tabular}{|c|c|c|c|c|}
\hline \multirow{4}{*}{$\begin{array}{l}\text { Category } 3 \\
\text { AUS/FLUS }\end{array}$} & Colloid Nodule & 3 & FP & \multirow{4}{*}{$50 \%$} \\
\hline & Adenomatous nodule & 1 & FP & \\
\hline & Cystic nodule & 1 & FP & \\
\hline & Papillary cancer & 5 & $\mathrm{TP}$ & \\
\hline \multirow{12}{*}{$\begin{array}{c}\text { Category } 4 \\
\text { FN/SFN }\end{array}$} & Colloid Nodule & 2 & FP & \multirow{12}{*}{$28 \%$} \\
\hline & Adenomatous nodule & 1 & FP & \\
\hline & Hyperplastic nodule & 1 & FP & \\
\hline & Toxic adenoma & 1 & FP & \\
\hline & Hashimoto's thyroiditis & 3 & FP & \\
\hline & Follicular adenoma & 15 & TP & \\
\hline & Hurthle adenoma & 3 & $\mathrm{TP}$ & \\
\hline & Papillary cancer & 5 & $\mathrm{TP}$ & \\
\hline & Follicular cancer & 4 & TP & \\
\hline & Hurthle cancer & 1 & $\mathrm{TP}$ & \\
\hline & Lymphoma & 1 & $\mathrm{TP}$ & \\
\hline & NIFTP & 2 & $\mathrm{TP}$ & \\
\hline \multirow{7}{*}{$\begin{array}{c}\text { Category } 5 \\
\text { Suspicious } \\
\text { for Malignancy }\end{array}$} & Hyperplastic nodule & 2 & FP & \multirow{7}{*}{$36 \%$} \\
\hline & Hashimoto's thyroiditis & 2 & FP & \\
\hline & Follicular adenoma & 1 & $\mathrm{TP}$ & \\
\hline & Hurthle adenoma & 1 & $\mathrm{TP}$ & \\
\hline & Papillary cancer & 3 & $\mathrm{TP}$ & \\
\hline & Follicular cancer & 1 & $\mathrm{TP}$ & \\
\hline & NIFTP & 1 & TP & \\
\hline Category 6 Malignant & Papillary cancer & 3 & TP & $100 \%$ \\
\hline
\end{tabular}

FNAC: Fine needle aspiration cytology, AUS/FLUS: Atypia undetermined significance (AUS) or Follicular lesion of undetermined significance (FLUS), FN/SFN: Follicular neoplasia (FN) or Suspicious Follicular neoplasia (SFN), NIFTP: NON invasive follicular thyroid neoplasia with papillary like features, TN: True negative, TP: True positive, FN: False negative, FP: False Positive.

The performance of FNAC in the diagnosis of thyroid neoplasms calculated by numerous tests is available:

1) True positive (TP) = the number of cases correctly identified as having thyroid neoplasm

2) False Positive (FP) = the number of cases incorrectly identified as having thyroid neoplasm

3) True Negative $(\mathrm{TN})=$ the number of cases correctly identified as not having thyroid neoplasm

4) False Negative (FN) = the number of cases incorrectly identified as not having thyroid neoplasm

5) Sensitivity measures the percentage of patients who are correctly identified 
as having thyroid neoplasms. Thus, sensitivity $=\mathrm{TP} /(\mathrm{TP}+\mathrm{FN})$

6) Specificity measures the percentage of patients who are correctly identified as not having thyroid. Thus, specificity $=\mathrm{TN} /(\mathrm{TN}+\mathrm{FP})$

7) Accuracy measures the ability of fine-needle cytology to correctly identify cases with thyroid neoplasms and cases without thyroid neoplasms. Thus, accuracy $=(\mathrm{TP}+\mathrm{TN}) /(\mathrm{TP}+\mathrm{FP}+\mathrm{TN}+\mathrm{FN})$

8) Predictive value positive is the proportion of positives that correspond to the presence of the thyroid neoplasm. Thus, predictive value positive $=\mathrm{TP} /(\mathrm{TP}+$ FP)

9) Predictive value negative is the proportion of negatives that correspond to the absence of the thyroid neoplasm. Thus, predictive value negative $=\mathrm{TN} /(\mathrm{TN}$ $+\mathrm{FN})$.

Table 11 Overall performance of fine needle aspiration cytology in the diagnosis of thyroid neoplasia Sensitivity $61.33 \%$, specificity $71.66 \%$, accuracy $64.44 \%$, positive predictive value $73.01 \%$ and negative predictive value $59.72 \%$.

\subsection{Histopathology Findings}

135 patients with solitary thyroid nodule after operation results of histopathology of them 100/135 patients (74\%) diagnosis as benign thyroid nodule and $35 / 135$ patients (26\%) diagnosis as thyroid cancer (Table 12, Table 13), show the post-operative Histopathology was malignant solitary thyroid nodule 35 (26\%) and Benign solitary thyroid nodule in $100(74 \%)$, and, of that Benign non neoplastic $60(44 \%)$ including colloid nodule $20(15 \%)$ patients, adenomatous nodule $13(10 \%)$ patients, hyperplastic nodule $12(9 \%)$, cystic nodule $5(4 \%)$ patients, chronic thyroiditis 7 (5\%) patients (Hashimoto's and lymphocytes thyroiditis) and toxic adenoma $3(2 \%)$ patients. The benign neoplastic nodule 40

Table 11. Overall performance of fine. Needle aspiration cytology in diagnosis of thyroid neoplasm.

\begin{tabular}{lc}
\hline \multicolumn{1}{c}{ Performance } & $\%$ \\
\hline Sensitivity & $61.33 \%$ \\
Specificity & $71.66 \%$ \\
Accuracy & $64.44 \%$ \\
Positive predictive value & $73.01 \%$ \\
Negative predictive value & $59.72 \%$ \\
\hline
\end{tabular}

Table 12. Solitary thyroid nodule histopathology.

\begin{tabular}{lcccccc}
\hline \multicolumn{1}{c}{ Histopathology } & $\begin{array}{c}\text { Number of } \\
\text { Patients } \\
(\mathrm{N}=135)\end{array}$ & $\%$ & $\begin{array}{c}\text { Female } \\
(\mathrm{N}=126)\end{array}$ & $\%$ & $\begin{array}{c}\text { Male } \\
(\mathrm{N}=9)\end{array}$ & $\%$ \\
\hline Solitary Thyroid Benign Nodule & 100 & $74 \%$ & 95 & $75 \%$ & 5 & $56 \%$ \\
Solitary Thyroid Malignant Nodule & 35 & $26 \%$ & 31 & $25 \%$ & 4 & $44 \%$ \\
\hline
\end{tabular}


Table 13. Solitary thyroid nodule post operation histopathology results.

\begin{tabular}{lcc}
\hline \multicolumn{1}{c}{ Post-operative histopathology } & $(\mathrm{N}=135)$ & $\%$ \\
\hline Benign non neoplastic & 60 & $44 \%$ \\
Benign and neoplastic & 40 & $30 \%$ \\
Malignant & 35 & $26 \%$ \\
\hline
\end{tabular}

(30\%) patients including follicular adenoma 28 (21\%), Hurthle cell adenoma 6 (4.4\%) patients, and 6 (4.4\%) non invasive follicular neoplasia with papillary features (NIFTP).

Twenty patients had benign colloid goiter, 4 of whom had cystic degeneration and hyperplastic changes, and 13 patients had benign adenomatous goiter, 4 of whom had cystic degenerative changes.

Twelve patients had benign hyperplastic nodular goiter, 2 of whom had cystic changes and marked fibrosis and calcification. And one them with hyperplastic papillary nodule in benign nodular goiter, five patients with benign cystic nodule 3 of them with hemorrhagic cystic nodule and 2 cases colloid cystic nodule, seven patients with chronic thyroiditis (Hashimoto's and lymphocytes thyroiditis), of them 3 cases with hypothyroidism and last three patients of benign non neoplastic nodule ware toxic adenoma with hyperthyroidism with average nodule size $4-5 \mathrm{~cm}$.

28 patients with benign follicular adenoma 3 of them with lymphocytic thyroiditis and one case with cystic degenerative changes, 6 patients with benign Hurthle cell adenoma (oncocytic neoplasm) and 6 patients with Non invasive follicular thyroid neoplasia with papillary nuclear like features (NIFTP), This type of thyroid tumor was previously classified non invasive encapsulated follicular variant of papillary thyroid cancer, but before few years reclassified this tumor as non-malignant because character by absent capsular, vascular invasion, tumor necrosis, high mitotic activity and have indolent behavior and may be over treatment if classify as type of cancer, all 6 patients (NIFTP) were female, between age 22 - 58 years, mean 40.83 years, median age 41 year, with standard deviation 12.38. Four patients were diagnosed with Lt Solitary thyroid nodules, and 2 patients were diagnosed with Rt Solitary thyroid nodules. The average size was $2-4 \mathrm{~cm}$ in 3 patients, $1-2 \mathrm{~cm}$ in 1 patient and $4-5 \mathrm{~cm}$ in 2 patients. Fine needle aspiration cytology showed benign cytology in 3 patients, follicular neoplasia in 2 patients and suspicious nodules in one patient, all 6 patients were euthyroid before the operation, 3 patients underwent Lt hemithyroidectomy, and 2 patients underwent Rt hemithyroidectomy. The (NIFTP) Considering this term benign and not followed by total thyroidectomy, only follow-up is needed.

Only One patient underwent total thyroidectomy because it was in the suspicious category, that patient developed postoperative temporary hoarseness that improved after a few weeks.

In Table 14, Histopathology subtype results were malignant solitary thyroid nodule in 35 (26\%) patients, 26 (74\%) papillary thyroid cancer (classical papillary 
Table 14. Solitary thyroid nodule histopathology results with its subtypes.

\begin{tabular}{llcc}
\hline Post-operative histopathology & \multicolumn{1}{c}{ Subtypes } & (N = 135) & \\
\hline & Colloid Nodule & 20 & $15 \%$ \\
& Adenomatous goiter & 13 & $10 \%$ \\
Benign non neoplastic & Hyperplastic nodule & 12 & $9 \%$ \\
& Cystic nodule & 5 & $4 \%$ \\
& Chronic thyroiditis & 7 & $5 \%$ \\
& Toxic adenoma & 3 & $2 \%$ \\
\hline \multirow{3}{*}{ Benign and neoplastic } & Follicular adenoma & 28 & $21 \%$ \\
& Hurthle cell adenoma & 6 & $4.4 \%$ \\
& Non invasive Follicular Thyroid Neoplasia & 6 & $4.4 \%$ \\
& with papillary like features (NIFTP) & & \\
\hline & Papillary Thyroid cancer & 26 & $19 \%$ \\
& Follicular Thyroid cancer & 5 & $4 \%$ \\
& Hurthle cell carcinoma & 1 & $0.7 \%$ \\
& Medullary Thyroid cancer & 1 & $0.7 \%$ \\
Malignant & Lymphoma & 1 & $0.7 \%$ \\
& Anaplastic cancer & $0.7 \%$ \\
\hline
\end{tabular}

thyroid cancer 10 cases, papillary micro carcinoma 3 case and 13 were reported as the follicular variant of papillary carcinoma (FVPTC), 5 (14\%) Follicular cancer. 1 (3\%) Hurthle cell carcinoma, 1 (3\%) medullary thyroid cancer, 1 (3\%) non-Hodgkin lymphoma, and 1 (3\%) anaplastic carcinoma.

\subsection{Management}

Depending on the interpretation of the FNAB cytological specimen, management consists of observation, levothyroxine suppression therapy, or surgery.

Patients with benign solitary thyroid nodules may undergo observation or levothyroxine suppression therapy as the initial treatment modality. Levothyroxine is typically administered for $6-12$ months to determine if the solitary thyroid nodule decreases in size. If the nodule decreases in size after treatment with levothyroxine, this medication is discontinued, with follow-up examination of the thyroid nodule in 3 - 6 months. However, if a benign solitary thyroid nodule increases in size, a repeat trial of levothyroxine and repeat FNAB may be indicated. Additionally, growth of a thyroid nodule during levothyroxine therapy is a strong indication for surgery.

No consensus exists regarding the degree of thyroid suppression or the efficacy of levothyroxine therapy. In fact, many endocrinologists no longer recommend thyroid suppression because of potential long-term adverse effects, such as osteoporosis and cardiac arrhythmias. Still others maintain a thyroid-stimulating hormone (TSH) level ranging from $0.1-0.3 \mathrm{mU} / \mathrm{L}$ rather than suppressing to the 
lowest limits of detectability to avoid immediate toxicity and long-term side effects.

Solitary thyroid nodules that are malignant, suspicious, or indeterminate on FNAB require excisional biopsy in the form of thyroidectomy. Considerable controversy exists regarding the extent of surgery for malignant, suspicious, or indeterminate solitary thyroid nodules.

\subsection{Type of Surgery and Operative Findings}

Patients with solitary thyroid nodules who underwent surgical procedures.

In Table 15, there were 154 operations for 135 patients with solitary thyroid nodule, 126 patients (93\%) female and 9 (7\%) male patients aged 14 - 65 years.

One hundred thyroid operations were performed for 100 patients with benign solitary thyroid nodules, and 54 thyroid operations were performed for 35 patients with malignant solitary thyroid nodules.

Rt hemithyroidectomy for 70 patients with Rt Solitary thyroid nodule, 60 cases was benign Solitary thyroid nodule, 9 cases followed by completion thyroidectomy after results of histopathology confirm malignant cancer and one case result of histopathology was papillary micro carcinoma $1-2 \mathrm{~cm}$ was enough treat by Rt hemithyroidectomy.

Table 15. Solitary thyroid nodule surgical procedures.

\begin{tabular}{|c|c|c|c|}
\hline Surgical procedure & $\begin{array}{l}\text { Benign } \\
\mathrm{N}=100\end{array}$ & $\begin{array}{l}\text { Malignant } \\
\mathrm{N}=54\end{array}$ & $\begin{array}{c}\text { Total } \\
\mathrm{N}=154\end{array}$ \\
\hline RT Hemithyroidectomy & 60 & 1 & 61 \\
\hline LT Hemithyroidectomy & 22 & 0 & 22 \\
\hline Rt Hemithyroidectomy follow by completion thyroidectomy & 0 & 9 & 9 \\
\hline Lt Hemithyroidectomy follow by completion thyroidectomy & 0 & 10 & 10 \\
\hline $\begin{array}{l}\text { Completion thyroidectomy with central lymph nodes } \\
\text { dissection }\end{array}$ & 0 & 17 & 17 \\
\hline $\begin{array}{l}\text { Completion thyroidectomy without central lymph nodes } \\
\text { dissection }\end{array}$ & 0 & 2 & 2 \\
\hline Total thyroidectomy with central lymph nodes dissection & 0 & 2 & 2 \\
\hline Total thyroidectomy & 14 & 8 & 22 \\
\hline $\begin{array}{l}\text { Total thyroidectomy with Selective Rt lymph nodes } \\
\text { dissection level } 2\end{array}$ & 2 & 1 & 3 \\
\hline $\begin{array}{l}\text { Total thyroidectomy with Rt Functional Modified neck } \\
\text { dissection }\end{array}$ & 0 & 3 & 3 \\
\hline $\begin{array}{l}\text { Total thyroidectomy with Lt Functional Modified neck } \\
\text { dissection }\end{array}$ & 0 & 1 & 1 \\
\hline Subtotal thyroidectomy & 1 & 0 & 1 \\
\hline Near total thyroidectomy & 1 & 0 & 1 \\
\hline
\end{tabular}

Rt: Right, Lt: Left. 
Lt hemithyroidectomy for 32 patients with Lt Solitary thyroid nodule, of 22 cases was benign Solitary thyroid nodule and 10 cases followed by completion thyroidectomy when results of histopathology confirm malignant cancer.

19 Completion thyroidectomies after hemithyroidectomy when the result of the histopathology was cancer, 10 patients completed Rt hemithyroidectomy and 9 patients completed Lt hemithyroidectomy.

Completion thyroidectomy with central lymph node dissection was performed in 17 patients (16 papillary thyroid cancer and one medullary thyroid cancer), and completion thyroidectomy without central neck lymph node dissection was performed in two patients (follicular thyroid cancer and Hurthle cell cancer).

Total thyroidectomy for 22 patients, 16 patients Rt Solitary thyroid nodule and 6 patients Lt Solitary thyroid nodule, 14 patients with benign nodule and 8 patients with malignant solitary thyroid nodule (2 patients Lt Solitary thyroid nodule and 6 patients Rt Solitary thyroid nodule) treat by total thyroidectomy and results of histopathology was 3 patients papillary thyroid cancer, 4 patients follicular cancer, one anaplastic cancer. Here, papillary thyroid cancer was not followed by any type of neck dissection because total thyroidectomy depending on the FNAC result was false negative for malignancy.

Near total thyroidectomy for one patient Rt Solitary thyroid nodule Toxic adenoma.

Subtotal thyroidectomy for one patient Rt Solitary prominent thyroid nodule Toxic adenoma.

Total thyroidectomy with central lymph nodes dissection 2 patients after FNAC results was malignant category 6 (papillary thyroid cancer) one of them underwent Total thyroidectomy with central lymph nodes dissection with resection underlying soft tissue infiltrated and part of strap muscle involved in patient with papillary thyroid cancer infiltrated underlying soft tissue and muscle was complicated by Temporary hypocalcemia.

Total thyroidectomy With Modified Neck dissection 4 patients, 3 cases Total thyroidectomy with Rt modified Neck dissection one case complicated by Temporary hypocalcemia, 1 case Total thyroidectomy with Lt modified Neck dissection complicated by Temporary hypocalcemia and Total thyroidectomy with Selective Rt lymph nodes dissection in 3 patient one patient with papillary thyroid cancer and level 2 lymph nodes positive and 2 patients was suspicious category with Lymph nodes at level 3 by FNAC but Result of histopathology was benign Hashimoto's goiter.

Neck dissection was performed in 26 patients, 24 of whom had malignant nodules, 6 of whom showed metastatic deposits in the lymph nodes. Five patients had papillary thyroid cancer, one patient had non-Hodgkin lymphoma in the background of Hashimoto's thyroiditis, and two patients had benign thyroid nodules and underwent selective lymph node dissection because FNAC gave us false positive results. The patient underwent total thyroidectomy with Rt selective lymph node dissection level 3 , but the result of histopathology was a hyper- 
plastic nodule with marked fibrosis and calcification. Another case result of the histopathology was Hashimoto's thyroiditis, 100 and thyroid operation for 100 patients with benign solitary thyroid nodules was distributed as follows.

60 Rt hemithyroidectomy, 22 Lt hemithyroidectomy, 14 total thyroidectomy and 2 total thyroidectomies with selective Rt neck lymph node dissection (for these 2 cases, FNAC was suspicious category with clinical lymph nodes). One case result of the histopathology was benign hyperplastic nodule with marked fibrosis and calcification also this case complicated by Temporary hypocalcemia, Other case result of the histopathology was hoshanot's thyroiditis), One case subtotal thyroidectomy for Solitary toxic adenoma and One case near total thyroidectomy for Solitary toxic adenoma.

Additionally, cancer was distributed according to surgical operation (Table 15), 17 patients underwent complete thyroidectomy with central lymph node dissection. Sixteen papillary thyroid cancer, 1 medullary thyroid cancer, 9 Rt solitary thyroid nodules proved thyroid cancer after Rt hemithyroidectomy, and 8 Lt solitary thyroid nodules proved thyroid cancer after Lt hemithyroidectomy. all followed by completion thyroidectomy with central dissection in 17 cases.

Two patients underwent completion thyroidectomy without central neck lymph nodes dissection after Lt hemithyroidectomy with results of histopathology one case follicular thyroid cancer and other case Hurthle cell cancer.

Eight patients with solitary thyroid nodules (2 patients had Solitary thyroid nodules, and 6 patients had Solitary thyroid nodules) were treated by total thyroidectomy. 3 papillary thyroid cancer, 4 follicular cancer, and 1 anaplastic cancer. Here, papillary thyroid cancer was not followed by any type of neck dissection because total thyroidectomy depending on the FNAC result was false negative for malignancy.

Two patients with solitary thyroid nodules (Rt Solitary thyroid nodules) were treated by total thyroidectomy and central lymph node dissection. After FNAC was true positive for malignancy, one case was the result of papillary thyroid cancer histopathology on the background of Hashimoto's thyroiditis, and the other case was papillary thyroid cancer with soft tissue infiltration that was resected with part of the strap muscle involved and positive lymph nodes.

One patient with a solitary thyroid nodule (Rt Solitary thyroid nodule) was treated by total thyroidectomy and selective Rt Neck lymph node dissection level 2. The results of histopathology were papillary thyroid cancer of one lobe and free of other lobes with capsular and lymph vascular invasion. Metastatic Deposit of Tumor in Two Cervical Lymph Nodes (2/4). AJCC TNM STAGING [pT3, $\mathrm{N} 1, \mathrm{Mx}]$.

Four patients underwent thyroidectomy with modified neck lymph node dissection (one Lt apparently thyroid nodule) FNAC metastasis papillary thyroid cancer by total thyroidectomy with functional Lt modified neck dissection, resulting in histopathology papillary thyroid cancer with positive lymph nodes. (3 cases Rt Solitary thyroid nodule one of them Rt apparent thyroid nodule FNAC adenocarcinoma thyroid origin and one case Recurrence papillary thyroid can- 
cer 20 years after thyroid surgery with positive lymph node Result of histopathology was these cases (infiltrating Papillary thyroid cancer with positive lymph node), and third one high suspicious vs follicular thyroid neoplasia Result of histopathology was (Lymphoma non Hodgkin large cell on back ground Hashimoto's thyroiditis).

One patient with a solitary thyroid nodule (Rt solitary thyroid nodule) treated by Rt hemithyroidectomy histopathology was diagnosed with papillary thyroid cancer. Intrathyroidal encapsulated follicular variant for 15 years female no family history and nodule size $1-2 \mathrm{~cm}$ was not follow by completion thyroidectomy because low risk. And follow up for 5 years no recurrent until now.

In Table 16, types of neck lymph node surgical dissection and metastatic deposits in the lymph nodes were seen in 6 of the 24 patients who had undergone lymph node dissection. Central node dissection was performed in 19 (1 positive) patients, right side modified neck dissection (MND) in 3 (3 positive) patients, Lt side modified neck dissection in one patient (1 positive) and Rt selective neck lymph node dissection in 1 patient ( 1 positive).

\subsection{Complications}

In Table 17, complications after thyroidectomy for solitary thyroid nodules appear.

12/135 patients $(8.88 \%)$, all female patients, 7 cases post Lt Solitary thyroid nodule and 5 cases post Rt Solitary thyroid nodule. 6/135 (4\%) and 6/100 (6\%) patients with benign nodule, $6 / 135$ (4\%) and 6/35 (17\%) patients with malignant nodule.

Table 16. Type of surgical neck dissection.

\begin{tabular}{lcc}
\hline \multicolumn{1}{c}{ Type of neck dissection } & $\begin{array}{c}\text { Number of patients } \\
\text { with neck dissection } \\
(\mathrm{N}=24)\end{array}$ & $\begin{array}{c}\text { Number of patients } \\
\text { with positive lymph node } \\
(\mathrm{N}=6)\end{array}$ \\
\hline Central neck lymph nodes dissection & 19 & 1 \\
Selective neck lymph nodes dissection & 1 & 1 \\
Rt Modified neck lymph nodes dissection & 3 & 3 \\
Lt Modified neck lymph nodes dissection & 1 & 1 \\
\hline
\end{tabular}

Table 17. Solitary thyroid nodule common post-operative complication.

\begin{tabular}{lcccc}
\hline \multicolumn{1}{c}{ Complications } & $\begin{array}{c}\text { Total } \\
(\mathrm{N}=12 / 135)\end{array}$ & $\%$ & $\begin{array}{c}\text { Benign } \\
\mathrm{N}=6\end{array}$ & $\begin{array}{c}\text { Malignant } \\
\mathrm{N}=6\end{array}$ \\
\hline Temporary hypocalcemia & 9 & $7 \%$ & 5 & 4 \\
Permanent hypocalcemia & 0 & & & 2 \\
Temporary hoarseness & 3 & $2 \%$ & 1 & \\
Permanent Hoarseness & 0 & & & \\
Other Complication & 0 & & & \\
\hline
\end{tabular}


Temporary hypocalcemia 9/135 patients (7\%), 5/135 (4\%) and 5/100 (5\%) patients with benign solitary thyroid nodule, 4/135 (3\%) and 4/35 (11\%) patients with malignant thyroid nodule, 4 RT Solitary thyroid nodule and 5 Lt Solitary thyroid nodule, All patients hypocalcemia symptoms appear 24 - 48 hours after operation with patients still at admission with Upper limb pain and numbness most common follow by carpopedal spasm, All response to oral calcium supplement But some time start by i.v infusion, Completely resolved symptoms and stop treatment 1 to 8 weeks But mostly second week.

1 patient 26 years female Post total thyroidectomy diagnosed clinical as Rt Solitary thyroid nodule (Toxic adenoma) Result FNAC was suspicious category with Rt clinical lymph nodes level 3 Patient underwent Total thyroidectomy with Rt selective lymph nodes dissection level 3 but Result of histopathology was hyperplastic nodule with marked fibrosis and calcification developed temporary hypocalcemia was improved after few weeks.

Three patients after total thyroidectomy with Hashimoto's thyroiditis and lymphocytic thyroiditis. One case post total thyroidectomy with follicular adenoma, 3 cases post Total thyroidectomy with central lymph nodes dissection with papillary thyroid cancer infiltrated, One case post Total thyroidectomy with Selective Rt lymph nodes dissection with papillary thyroid cancer with lymph node metastasis and One case post Total thyroidectomy with modified Rt and Lt neck dissection. All females were aged 20 - 62 years. All nodules were hardly fixed, with an average nodule size of $2-5 \mathrm{~cm}$.

Five patients had Lt Solitary thyroid nodules, and 4 patients had Rt Solitary thyroid nodules. Temporary horsiness 3 patients $(2.22 \%), 2 / 35$ (6\%) patients with malignant nodule and One/100 (1\%) patient with benign nodule, One RT Solitary thyroid nodule, 2 Lt Solitary thyroid nodule, 3 cases all female with age $60,40,29$ mostly due to the laryngeal edema post thyroidectomy.

One case after total thyroidectomy for anaplastic thyroid cancer older age infiltrated tumor big tumor size $6-9 \mathrm{~cm}$ and 1 case after total with selective Rt Neck dissection for patients with papillary thyroid cancer with lymph node metastasis and 1 case post Lt hemithyroidectomy for patient with Noninvasive follicular neoplasia with papillary like features was 29 years old female developed temporary hoarseness was improved after few weeks. All patients appeared hoarseness directly after the operation; they received a warm saline nebulizer and dexamethasone for 24 - 48 hours, and the hospital stay was not completely improved by 3 - 6 months.

The postoperative hospital stays ranged from one to 3 days, and the mean hospital stay was 2 days.

Follow-up ranged from one to 48 months with a mean follow-up of $12.1 \pm$ 14.2 months.

\section{Discussion}

Thyroid nodules refer to localized lesions within the thyroid gland that are 
palpably or radiologically distinct from the surrounding thyroid parenchyma [22].

Because of the high risk for malignancy, surgeons tend to treat them with a high degree of suspicion and plan treatment in a systematic manner. Clinically, STNs are common and are present in up to $50 \%$ of the elderly population. The majority of STNs are malignant [2] [10] [11].

Therefore, it is recommended that all thyroid nodules $>1 \mathrm{~cm}$ in size should undergo evaluation. This includes both palpable and nonpalpable nodules or nodules detected by imaging.

Benign causes of thyroid nodules include colloid nodules, hyperplastic nodules, and adenomatous nodules. Occasionally, nodularity is noticed in patients with Hashimoto's thyroiditis and toxic adenoma. Malignant causes of nodules include thyroid cancer, lymphoma and metastasis to the thyroid gland [22].

In our country, a different study was performed on thyroid cancer Al-Hureibi, Abdulmughni, Y. Thyroid FNAC. (2003) [23], Abdulghani, Yasser A., et al. thyroid cancer (2004) [24], Al-Jaradi, Mansour, et al. Prevalence of thyroid cancer (2005). [25], Al-Sharafi, Butheinah A., et al. thyroid cancer (2020). [26], and Burkan N, et al. (2021) [27], during our study period, 135 patients had solitary thyroid nodules; there were 126 (93\%) females with STNs and 9 (7\%) male patients with solitary thyroid nodules.

Thyroid nodules are more common in females similar as noted in the previous study [2] [6].

Solitary thyroid nodules were 10 - 11 times more common in females as compared to males [2] [10], Our study showed that solitary thyroid nodules were 14 times more common in female than male.

In our study 135 Patients with Solitary Thyroid Nodule b/n age 14 - 65 years, median age 41 years, mode 45 years, average mean age 39.76 years, range 51 years and Stander deviation 13.98. The age range and mean slightly wide, and higher compared with previous study by (Gupta) [10].

In our study Solitary thyroid nodule, more Common in age group between 21 - 30 years old are about 50 patients and the next age group between 41 - 50 years old are about 29 patients. That mean second decade involved by majority of the patients (37\%) this is lower than previous study by Gupta [10], and Dorairajan and Jayashree in that third decade of life majority of the patients involved (44\%).

Evaluation of solitary thyroid nodules requires the collaboration of the primary care physician, endocrinologist, pathologist, radiologist, and head and neck surgeon to provide comprehensive and appropriate management of this clinical entity [28].

Preliminary investigation should include careful history and thorough clinical examination and thyroid function tests. Combination with thyroid ultrasound and FNAC becoming relevant in the management of thyroid nodules [22] [29]. Further investigation should be considered if the following factors are present in addition to the thyroid nodule like male gender, extremes of age $(<20$ or $>70$ years), history of neck irradiation, nodule $>4 \mathrm{~cm}$ in size or the presence of any 
pressure symptoms [22]. None of our patients in the study group had history of radiation exposure.

Patients under the age of 20 or over 70 years with thyroid nodules have an increased risk of malignancy, as do men. A history of persistent hoarseness, dysphagia, or dyspnea also increases the risk, although these symptoms may also occur with benign nodules. Rapid painless growth of a solid nodule is concerning and raises the suspicion for thyroid cancer [30].

Numerous studies have documented that the risk of malignancy in patients with thyroid nodules is $5 \%-17 \%$, whether detected by palpation or ultrasonography.

There were 135 cases of clinically detected STNs with available ultrasound findings in the study group. Thirty-five (26\%) (3:1) clinically detected STNs were reported as malignant in the final HPE. This high incidence of malignancy reported in our study is similar to that of Tai et al. [2]. A total of $36.6 \%$ (97) of the 265 patients also reported a $20 \%$ and $42.27 \%$ incidence in the papers [10] [11]. were proven to be malignant, which was higher than the general incidence of malignancy of 5\%. It seems that STN has a higher risk of malignancy, so in this condition, we should focus on the potential danger to all these patients.

A retrospective study by Keh et al. of 61 patients found that $75.4 \%$ of solitary thyroid nodules had a neoplastic pathology and $34.4 \%$ were malignant [31].

The rise in incidence seems to be attributable both to the growing use of diagnostic imaging and fine-needle aspiration biopsy, which has led to enhanced detection and diagnosis of subclinical nodules and early diagnosis of low-risk lesions [32] [33].

The fact that the malignant percentages obtained in this study were higher is partly due to the pattern we used for selecting patients. In other words, we selected the cases from surgery wards, whereas other studies included in their experiments all the cases that were subjected to FNAC. As noted above, the risk of malignancy in this group has been reported to be $26 \%$; however, a higher rate has also been reported. [34] [35] [36].

In our study, 35 patients were diagnosed with malignant solitary thyroid nodules; 31 patients were female, and 4 patients were male.

Among female patients, 31/126 (25\%) were reported as malignant in histopathology results. Additionally, malignancy was found in 4 (44\%) out of 9 male patients with solitary thyroid nodules. Hence, thyroid nodules predominate in females [2] [6] and the increased incidence of malignant thyroid nodules in males noted in our study are similar to those of Tai et al. (36\%) [2] [37].

The age of patients with malignant tumors ranged from $\mathrm{b} / \mathrm{n} 15$ - 62 years, median age 35 years, mode 23 years, average mean age 35.97 years and standard deviation 11.91.

In our study, malignant solitary thyroid nodules were more common in the age group between 21 - 30 years old, with approximately 12 patients (34\%).

Different studies have shown different results regarding the role of age as a risk factor for thyroid malignancy. Pinchot et al. [38], and Muratli et al. [34], 
reported that thyroid carcinoma prevalence was higher in the elderly than in others, while Rosario et al. did not observe a significant difference between the ages of the patients [39]. Nevertheless, some studies, including ours, revealed that the prevalence of thyroid carcinoma is higher in younger patients [40] [41].

In our study, most solitary thyroid nodules, even benign or malignant nodules, were between $2.1-4 \mathrm{~cm}$. The size of the nodule had no relation with malignancy in our study, which was also reported by Tai et al. [2]. A study by Kamran et al. opined that the risk of follicular carcinomas and other rare thyroid malignancies increases as nodules enlarge [42]. However, no such association with size was seen in our cases.

Usually, the size of the thyroid nodule does not predict the likelihood of thyroid cancer. Only $8 \%$ of incidentally found thyroid nodules measuring $<5 \mathrm{~mm}$, $15 \%$ of nodules measuring $5-10 \mathrm{~mm}$, and $13 \%$ of nodules measuring $10-15$ mm are malignant [43].

The results of this study revealed that the size of thyroid nodules is not reliable at predicting malignancy and should not be applied in surgical decision making. [44] [45], was similar to our study.

A study by Valderrabano et al. indicated that regardless of size, most solitary cytologically indeterminate thyroid nodules can be successfully treated with thyroid lobectomy. Comparing indeterminate tumors of less than $4 \mathrm{~cm}$ with those 4 $\mathrm{cm}$ or greater, size was not seen as a categorical or continuous variable in relation to cancer rate. Moreover, the prevalence of extrathyroidal extension, positive margins, lymph vascular invasion, lymph node metastasis, and distant metastasis did not differ by size. The investigators also found the majority of malignant tumors in both size groups to be low-risk lesions [46].

In our study $(72 \%, 63 \%)$, the Rt-side thyroid was more affected by either benign or malignant solitary thyroid nodules. A similar study by Liceity et al. 9 noticed that there was a predilection for benign and malignant nodules to occur in the right lobe, and Robinson et al. 1 also found that in $40 \%$ of cases, the nodules were located in the right lobe [47].

In our study Most common results of histopathology was Benign solitary thyroid nodule in 100 (74\%), of that Benign non neoplastic 60 (44\%) including colloid nodule 20 (15\%) patients, adenomatous nodule 13 (10\%) patients, hyperplastic nodule $12(9 \%)$, cystic nodule 5 (4\%) patients, chronic thyroiditis 7 (5\%) patients (Hashimoto's and lymphocytes thyroiditis) and toxic adenoma $3(2 \%)$ patients. The benign neoplastic nodule $40(30 \%)$ patients including follicular adenoma 28 (21\%), hurtle cell adenoma $6(4.4 \%)$ patients, and $6(4.4 \%)$ non invasive follicular neoplasia with papillary features (NIFTP).

Malignant solitary thyroid nodules appeared in 35 (26\%) patients, and papillary thyroid cancer $(74 \%)$ was the most common, followed by follicular thyroid cancer (14\%), followed by equal frequency (3\%), Hurthle, medullary, lymphoma and anaplastic thyroid cancer.

Malignant solitary thyroid nodules appeared in 3/6 (50\%) patients with hypothyroidism before the operation. The histopathology results showed malignant 
nodules such as papillary thyroid cancer on a background of Hashimoto's thyroiditis, one of whom had lymph node metastasis. This means a higher risk for malignant transformation, especially papillary thyroid cancer, than lymphoma [48].

Ultrasonography is the most cost-effective imaging procedure and is highly sensitive in assessing nodule size and number. There are ultrasound patterns that suggest malignancy such as irregular shape, ill-defined borders, hypo echogenicity, solid texture, heterogeneous internal echoes, microcalcification, absence of a halo, an anteroposterior to transverse diameter ratio $(\mathrm{A} / \mathrm{T})>1$, infiltration into regional structures, and suspicious regional lymph nodes [22].

Thyroid ultrasonography can be helpful in certain cases when it is used to guide FNAB. Data have suggested that ultrasonography-guided FNAB are preferable to palpation-guided FNAB [49].

Ultrasound may aid in the localization and examination of nodules, but FNA or excisional biopsy is necessary to definitively determine the presence of malignancy [50].

Addition, high-resolution ultrasound and ancillary testing in the form of molecular genetics and immunocytochemistry can improve diagnostic accuracy [51] [52].

The likelihood that the increased incidence of thyroid cancer is largely related to early detection by high-resolution ultrasound and discovery of subclinical thyroid nodules. [52] [53], is supported by evidence suggesting that survival rates for thyroid cancer have remained fairly stable [54].

In our study, 28 patients out of a total 35 (80\%) malignant cases had microcalcifications by thyroid ultrasound, in contrast to 10 of 100 (10\%) benign nodules. This finding suggests that in the presence of microcalcifications, the incidence of malignancy is more similar to that in a study by Kuo et al., which indicated that on ultrasonographic examination, the presence of calcifications within a thyroid lesion and nodule-like solid masses are independent factors for thyroid cancer, especially follicular thyroid carcinoma instead of follicular adenoma [55]. Additionally, an article by Rago et al. suggested that atypia at cytology and spot microcalcification at ultrasound were predictive of malignancy [56].

The presence of solid echogenicity contributes to an increased incidence of malignancy in comparison to either cystic or mixed echogenicity of the nodule. [2], our study showed that similar results were solid in 30/35 (86\%) patients with malignant nodules. The findings of our study also suggest that the presence of cervical lymphadenopathy is high in the presence of malignant thyroid nodules. Twenty-four of 35 (69\%) malignant nodules had lymph node enlargement compared with only 2 of 100 (2\%) benign nodules.

Noted male gander, solid nodule, hypoechoic, irregular borders, microcalcification, increased vascularity, and cervical lymphadenopathy are malignancy risk factors for solitary thyroid nodules study by Uyar et al. [2] [50] [55] [56] [57].

In our study, ultrasound revealed hypoechoic nodules in 33/35 (94\%) patients 
with malignant nodules and 15 (15\%) with benign nodules. The presence of hypoechoic nodules was high in the presence of malignant thyroid nodules, similar to the study by DS Cooper-Thyroid, 2009-Malignant lesions were found to be hypoechogenicity on ultrasound in almost $80 \%$ of cases. When the finding of hypoechogenicity lesion is combined with microcalcifications, irregular borders, and taller than wide shape, the sensitivity for malignancy increases. Simple cysts, hyperechogenic solid nodules, and spongiform architecture are all associated with benign lesions [50].

Papini et al. opined that ultrasound-guided FNAC should be performed on all 8 - $15 \mathrm{~mm}$ hypoechoic nodules with irregular margins, intranodular vascular spots or microcalcifications [58].

According to the literature, STNs have a higher risk of malignancy than multiple nodules [2].

In our study group, (26\%) (35/135) STNs were malignant (3:1) compared to that of multinodular goiter (24/72) (22.5\%). In a study from Nigeria, the authors described malignancy in 1 out of the 13 cases of STN (7.6\%) and twenty-four out of 160 cases of MNG (15\%) [59]. Hence, multinodularity does not necessarily exclude malignancy, as seen by our study group.

Male sex, normal thyroid volume, single nodularity, nodule hypoechogenicity, and blurred margins were also associated with malignancy, but size was not significantly associated with malignancy [56].

We noted that male sex, microcalcification, solid echogenicity of the nodule, and the presence of cervical lymphadenopathy were significantly associated with malignancy, as noted by Tai et al. [2].

Study by Yuan et al., however, indicated that the patterns of enhancement differ significantly between benign and malignant solitary thyroid nodules examined with real-time, contrast-enhanced ultrasonography, with most malignant lesions in the report demonstrating an irregular shape, an unclear boundary, and inhomogeneous and incomplete enhancement. The study involved 78 patients, including 41 with benign lesions and 37 with malignant nodules [60], and Desjardins et al. found that half of their patients with thyroid carcinoma had a cystic component in the tumor [61].

Fine-needle aspiration biopsy (FNAB) has become the most important tool in the assessment of solitary thyroid nodules [62].

Fine-needle aspiration cytology is recommended to be a cost-effective procedure in the initial assessment and management of thyroid nodules [2] [11]. It is recommended that every patient with a palpable thyroid nodule should undergo FNAC. USG-guided FNAC can lower the occurrence of nondiagnostic smears. Whenever we had problems in preoperative diagnosis by FNAC due to inadequate material or difficulty in aspiration by conventional methods, we repeated FNAC by USG guidance. In our study and previous study experience, noted a better yield of diagnostic cytological material with the help of USG-guided aspirations compared to blind FNAC [63] [64]. 
All our patients underwent FNAC by ultrasound guidance before surgery, as it helped us to decide the type of surgery to be undertaken. When the FNAC report was malignant or suspicious, total thyroidectomy was performed. In all other cases, hemithyroidectomy was performed, and a subsequent plan was decided based on a conclusive paraffin section report.

In a recent article, the authors emphasized the role of USG by suggesting that nodules with a nondiagnostic FNAC result in the setting of low-risk demographics and benign appearance at ultrasound can be followed with serial ultrasound examinations, thereby avoiding repeat FNAC. [65] These findings are in contrast to the recommended current guidelines to repeat FNAC after a nondiagnostic result [50].

Determining the nature of STNs is very important, as aggressive surgery may be regarded as an excessive mode of treatment. [2] We opted for surgery in all patients, as there is a high incidence of malignancy in STN patients, as reported in the literature [2]. The postoperative histopathology reports corroborated our findings, as $\sim 1 / 3$ of STNs were reported to be malignant.

study by Arul and Masilamani indicated that in cases of solitary thyroid nodules, fine-needle aspiration cytology reports using the Bethesda System for Reporting Thyroid Cytopathology correlate well with histopathologic diagnosis of these nodules, having a sensitivity, specificity, accuracy, positive predictive value, and negative predictive value of $94.4 \%, 97.6 \%, 95.8 \%, 98.1 \%$, and $93.2 \%$, respectively [66].

Al-hereby et al. study 2003 on 196 patients with nodular goiter fine needle aspiration having a sensitivity, specificity, accuracy, positive predictive value, and negative predictive value of $38 \%, 89.9 \%, 72 \%, 66.7 \%$, and $79.2 \%$, respectively [23].

In our study, thyroid fine needle aspiration had a sensitivity, specificity, accuracy, positive predictive value, and negative predictive value of $61.33 \%, 71.66 \%$, $64.44 \%, 73.1 \%$, and $59.72 \%$, respectively.

The sensitivity of FNA cytology in this study is low compared to published studies from outside countries where the sensitivity, specificity and accuracy of FNA cytology are more than $94 \%$. Which adversely affected the surgical decision making and the outcome. We should realize that negative FNA cytology does not exclude malignancy, and we have to seriously evaluate the situation and to rethink on how to raise the scale of sensitivity in FNA cytology in the diagnosis of thyroid nodules and to improve the level of expertise in cytology.

Yemen, as any developing country, lacks an accepted level of expertise in this field, something that makes it mandatory to continuously monitor and evaluate how valid this procedure is whose study reported. However, this high rate of malignancy is not surprising if we know that FNAC is currently routinely performed for most cases of thyroid nodules. This has led to a reduction in the number of unnecessary surgeries and consequently to a rise in the percentage reported for malignancy [35]. 
The respective risk of malignancy associated with each diagnostic category is as follows:

Non diagnosed, Benign-<1\%, Atypia (AUS) $-5 \%-10 \%$, Follicular neoplasm-20\% - 30\%, Suspicious for malignancy-50\% - 75\%, Malignant-100\%. [35].

In our study, the risk of malignancy for each Bethesda category was as follows:

Non diagnosed-17\%, Benign-21\%, Atypia (AUS) - 50\%, Follicular neoplasm-33\%, Suspicious for malignancy-45\%, Malignant-100\%.

The correlation between FNAC and histopathological diagnoses in our study shows the accuracy with which FNAC diagnosed follicular neoplasia. There were 14 cases of false negatives that had been reported as benign nodules by FNAC examination, and histopathological analysis showed follicular adenoma in 12 cases and Hurthle adenoma in 2 cases and 8 cases of false positives (FPs), diagnosed as follicular neoplasms by FNAC examination. Histopathological analysis showed that two of them were colloid nodular goiters, one adenomatous nodule, one hyperplastic nodule, one toxic adenoma and three Hashimoto's thyroiditis (chronic lymphocytic thyroiditis). There were 31 cases True positive (TP) cases, all case was follicular neoplasm by FNAC examination, by histopathological analysis, 15 cases were follicular adenoma, 3 cases were hurthel adenoma, noninvasive follicular thyroid neoplasia with Papillary features and 5 papillary carcinoma, 4 cases follicular carcinoma, hurthel cell carcinoma one case and one case lymphoma.

The risk of malignancy for each Bethesda category ranged from $6.9 \%$ (the "benign and nonneoplastic" category) to $100 \%$ (the "malignant" category). This wide range shows the power of the Bethesda system to differentiate and determine the probability of malignancy. The percentages obtained in our research were rather close to the figures reported in other studies: $6.9 \%$ versus $0 \%-3 \%$ (the "benign and non-neoplastic" category), 50\% versus 5\% - 15\% (AUS/FLUS), $37 \%$ versus $15 \%-30 \%$ (FN/SFN), $81.2 \%$ versus $60 \%-75 \%$ (the "suspicious for malignancy" category), and 100\% versus 97\% - 99\% (the "malignant" category). [35].

\subsection{Surgical Management}

154 thyroid operation for 135 patients with solitary thyroid nodule, 100 thyroid operation for 100 patients with benign solitary thyroid nodule and 54 thyroid operation for 35 patients with malignant solitary thyroid nodule, 102/154 (66\%) hemithyroidectomy either Rt or Lt side thyroid for benign or malignant solitary thyroid nodules but 19 patients of hemithyroidectomy followed by completion thyroidectomy when results of histopathology was malignant thyroid nodules.

Wagana and colleagues agreed that hemithyroidectomy is the most common operation performed in solitary thyroid nodules (81 operations were performed for solitary thyroid nodules, and the most common operations were lobectomy and isthmusectomy). They performed a retrospective review of all solitary thy- 
roid nodules excised over a 3-year period from $1^{\text {st }}$ January 1999 to $31^{\text {st }}$ December 2001. A simple protocol was used to manage this condition involving history, clinical examination, fine-needle aspiration of the lesion, and excision. Clinical diagnosis and operation were performed for patients who had solitary thyroid nodules over a 3-year period at Kayfabe Hospital [67].

We performed hemithyroidectomy in benign nodules as reported by FNAC. In those cases where postoperative HPE was reported as malignant by paraffin section, completion thyroidectomy of the remaining lobe was performed. Total thyroidectomy was performed in those cases where FNAC was reported to be suspicious of malignancy or malignancy.

Total thyroidectomy for 22 patients, 14 patients with benign nodule and 8 patients with malignant solitary thyroid nodule (2 patients Lt Solitary thyroid nodule and 6 patients Rt Solitary thyroid nodule) treat by total thyroidectomy and results of histopathology was 3 patients' papillary thyroid cancer, 4 patients' follicular cancer, one anaplastic cancer. Here, papillary thyroid cancer was not followed by any type of neck dissection because total thyroidectomy depending on the FNAC result was false negative for malignancy.

Near total or subtotal thyroidectomy for 2 patients Rt Solitary thyroid nodule Toxic adenoma.

Neck dissection was performed in 26 patients, 24 of whom had malignant nodules, 6 of whom showed metastatic deposits in the lymph nodes. Five patients had papillary thyroid cancer, one patient had non-Hodgkin lymphoma in the background of Hashimoto's thyroiditis, and two patients had benign thyroid nodules and underwent selective lymph node dissection because FNAC gave us false positive results. This patient underwent total thyroidectomy with Rt selective lymph node dissection level 3, but the result of histopathology was a hyperplastic nodule with marked fibrosis and calcification. Another case result of histopathology was Hashimoto's thyroiditis.

Central node dissection was performed in 19 ( 1 positive) patients, right side modified neck dissection (MND) in 3 ( 3 positive) patients, Lt side modified neck dissection in one patient (1 positive) and Rt selective neck lymph node dissection in 1 patient (1 positive).

Decision of neck dissection was made in those cases with either palpable lymph nodes in the neck or USG findings suggestive of lymphadenopathy. In some cases, the decision of lymph node dissection was made intraoperatively mainly for central nodes (level VI). Central node dissection was performed in all malignant cases with USG showing lymph node enlargement and in cases with enlarged intraoperative nodes.

Prophylactic central neck dissection in clinically node-negative patients remains controversial.

Calò, Pietro Giorgio, et al. found no statistically significant difference in the rates of locoregional recurrence between the three modalities of treatment. Total thyroidectomy appears to be an adequate treatment for clinically node-negative 
differentiated thyroid cancer. Prophylactic central neck dissection might be considered for differentiated thyroid cancer patients with large tumor sizes or extrathyroidal extension [68].

In a study by Chen, Lawrence, et al., compared with no prophylactic central neck dissection, prophylactic central neck dissection significantly reduced locoregional recurrence but was accompanied by numerous adverse effects.

Patients who underwent prophylactic central neck dissection had significantly lower locoregional recurrence and locoregional recurrence (odds ratio [OR] $0.65 ; 95 \%$ confidence interval [CI] 0.48 - 0.88) but significantly higher incidence rates of transient recurrent laryngeal nerve injury (OR 2.03; 95\% CI 1.32 - 3.13), transient hypocalcemia (OR 2.23; 95\% CI $1.84-2.70$ ), and permanent hypocalcemia (OR 2.22; 95\% CI 1.58 - 3.13) than those in the no prophylactic central neck dissection group [69].

\subsection{Intraoperative Assessment}

During my study, we noted that intraoperative assessment for solitary thyroid nodules was FNAC before surgery was benign, or follicular neoplasia should be assessed for hardness and fixation of nodules if hard and fixed nodules are best intraoperatively to make decisions to perform total thyroidectomy instead of hemithyroidectomy. We found hard and fixed nodules intraoperatively in 32/35 (91\%) patients diagnosed after the operation as thyroid cancer.

This means that intraoperative assessment of the hardness and fixation of the nodule and total thyroidectomy at that time are reduced require a second operation, completion thyroidectomy and complications.

\subsection{Complication of Surgery in Solitary Thyroid Nodules}

Complications postoperatively were temporary hypocalcemia and hoarseness of voice in 12 patients $12 / 135$ patients $9 \%$, all female patients; out of them $9(7 \%)$ patient, with temporary hypocalcemia and $3(2.2 \%)$ patient with temporary unilateral recurrent laryngeal nerve injury 7 cases post Lt Solitary thyroid nodule and 5 cases post Rt Solitary thyroid nodule. 6/135 (4\%) and 6/100 (6\%)patients with benign nodule and 6/135 (4\%) and 6/35 (17\%)patients with malignant nodule.

Temporary hypocalcemia 9/135 patients (7\%), 5/135 (4\%) and 5/100 (5\%) patients with benign solitary thyroid nodule, $4 / 135$ (3\%) and 4/35 (11\%) patients with malignant thyroid nodule.

Three patients (2.22\%) had temporary unilateral recurrent laryngeal nerve injury and laryngeal edema, 2/35 (6\%) patients had malignant nodules, and one/ $100(1 \%)$ patient had benign nodules.

\section{Conclusions}

The incidence of malignancy in STNs is indeed high. Clinically detected solitary nodules should be treated with a high degree of suspicion. Male patient and rapid 
growth by history and hard fixed nodules by clinical examination and hypoechoic, microcalcification and cervical lymphadenopathy on USG were seen more frequently in malignant nodules. FNAC is more accurate and helpful for diagnosing solitary thyroid nodules if aspiration under USG guidance and reading by experience histopathology. The type of surgery depends on preoperative evaluation, including history, clinical examination, ultrasound, FNAC result, and intraoperative assessment of the nodule. Male sex was identified as a risk factor for thyroid cancer, while age, number and size of nodules were not. The most common indication for surgery was a diagnosis of malignant disease when preoperative FNAC and US were inconclusive. There were fewer complications of thyroid surgery by experienced surgeons.

Intraoperative assessment for hardness and fixity of nodules and decision for total thyroidectomy at that time reduced the need for a second operation, such as completion thyroidectomy and its complications.

\section{Acknowledgements}

The authors wish to thank Dr Ghalib Al_Sady hospital manager to provide facilities and Mr. Adele Amari for his assistance with the statistical analysis and design.

\section{Contributions}

Burkan Nasr designed the study and wrote the manuscript. BN, MQ, SQ, AT and AG collected the data.

$\mathrm{BN}, \mathrm{YA}, \mathrm{MS}, \mathrm{MA}$ and AT planned the data analysis. And MQ and SQ reviewed the pathological data, AT, MA, and MS reviewed the radiological data. All the authors read, revised and approved the final manuscript.

\section{Conflicts of Interest}

The authors declare no conflicts of interest regarding the publication of this paper.

\section{References}

[1] Gharib, H. and Pupinid, E. (2007) Thyroid Nodules: Clinical Importance, Assessment, and Treatment. Endocrinology \& Metabolism Clinics of North America, 36, 707-735. https://doi.org/10.1016/j.ecl.2007.04.009

[2] Tai, J.D., Yang, J.L., Wu, S.C., Wang, B.W. and Chang, C.J. (2012) Risk Factors for Malignancy in Patients with Solitary Thyroid Nodules and Their Impact on the Management. Journal of Cancer Research and Therapeutics, 8, 379-383. https://doi.org/10.4103/0973-1482.103516

[3] Yeung, M.J. and Serpil, J.W. (2008) Management of the Solitary Thyroid Nodule. The Oncologist, 13, 105-112. https://doi.org/10.1634/theoncologist.2007-0212

[4] Spanheimer, P.M., Sugg, S.L., Lal, G., et al. (2011) Surveillance and Intervention after Thyroid Lobectomy. Annals of Surgical Oncology, 18, 1729-1733. https://doi.org/10.1245/s10434-010-1544-8 
[5] Zdon, M.J., Freedland, A.J. and Zarate, P.H. (2001) Follicular Neoplasms of the Thyroid: Predictors of Malignancy? The American Surgeon, 67, 880-884.

[6] Mazzaferro, E.L. (1993) Management of a Solitary Thyroid Nodule. The New England Journal of Medicine, 328, 553-559. https://doi.org/10.1056/NEJM199302253280807

[7] Tan, G.H. and Gharib, H. (1997) Thyroid Incidentalomas: Management Approaches to Nonpalpable Nodules Discovered Incidentally on Thyroid Imaging. Annals of Internal Medicine, 126, 226-231.

[8] Bongiovanni, M., Spittle, A., Raquin, W.C., Mazzuchelli, L. and Baloch, Z.W. (2012) The Bethesda System for Reporting Thyroid Cytopathology: A Meta-Analysis. Acta Cytologica, 56, 333-339. https://doi.org/10.1159/000339959

[9] La Vecchio, C., et al. (2015) Thyroid Cancer Mortality and Incidence: A Global Overview. International Journal of Cancer, 136, 2187-2195. https://doi.org/10.1002/ijc.29251

[10] Gupta, M., Gupta, S. and Gupta, V.B. (2010) Correlation of Fine Needle Aspiration Cytology with Histopathology in the Diagnosis of Solitary Thyroid Nodule. Journal of Thyroid Research, 2010, Article ID: 379051. https://doi.org/10.4061/2010/379051

[11] Iqbal, M., Mehmood, Z., Rasul, S., Amanullah, H., Shah, S.S. and Bokhara, I. (2010) Carcinoma Thyroid in Multi and Unimodular Goiter. Journal of College of Physicians and Surgeons Pakistan, 20, 310-312.

[12] Russ, G. (2016) Risk Stratification of Thyroid Nodules on Ultrasonography with the French TI-RADS: Description and Reflections. Ultrasonography, 35, 25-38. https://doi.org/10.14366/usg.15027

[13] Renuka, I.V., et al. (2012) The Bethesda System for Reporting Thyroid Cytopathology: Interpretation and Guidelines in Surgical Treatment. Indian Journal of Otolaryngology and Head \& Neck Surgery, 64, 305-311. https://doi.org/10.1007/s12070-011-0289-4

[14] Stace, F., et al. (2007) The Radiologist and the Cytologist in Diagnosing Thyroid Nodules: Results of Cooperation. La Radiologic Medica, 112, 597-602. https://doi.org/10.1007/s11547-007-0156-2

[15] Cibas, E.S. and Ali, S.Z. (2017) The 2017 Bethesda System for Reporting Thyroid Cytopathology. Thyroid, 27, 1341-1346. https://doi.org/10.1089/thy.2017.0500

[16] Alexander, E.K. (2008) Approach to the Patient with a Cytologically Indeterminate Thyroid Nodule. The Journal of Clinical Endocrinology \& Metabolism, 93, 4175-4182. https://doi.org/10.1210/jc.2008-1328

[17] Kumar, V., Abbas, A.K. and Aster, J.C. (2015) Robbins \& Cotran Pathologic Basis of Disease. 9th Edition, Elsevier, Philadelphia.

[18] Lloyd, R.V., Osamura, R.Y., Klöppel, G. and Rosai, J. (2017) WHO Classification of Tumours of Endocrine Organs. 4th Edition, IARC Publications, Lyon.

[19] Ali, S.Z. and Cibas, E.S. (2010) The Bethesda System for Reporting Thyroid Cytopathology, Vol. 11. Springer, New York. https://doi.org/10.1007/978-0-387-87666-5

[20] Theoharis, C.G.A., et al. (2009) The Bethesda Thyroid Fine-Needle Aspiration Classification System: Year 1 at an Academic Institution. Thyroid, 19, 1215-1223. https://doi.org/10.1089/thy.2009.0155

[21] Freitas, J.E. (2000) Therapeutic Options in the Management of Toxic and Nontoxic Nodular Goiter. Seminars in Nuclear Medicine, 30, 88-97. https://doi.org/10.1053/nm.2000.4597

[22] Unnikrishnan, A.G., et al. (2011) Endocrine Society of India Management Guide- 
lines for Patients with Thyroid Nodules: A Position Statement. Indian Journal of Endocrinology and Metabolism, 15, 2-8.

[23] Al-Hureibi, K.A., Al-Hureibi, A.A., Abdulmughni, Y.A., Aulaqi, S.M., Salman, M.S. and Al-Zooba, E.M. (2003) The Diagnostic Value of Fine Needle Aspiration Cytology in Thyroid Swellings in a University Hospital. Yemen Saudi Medical Journal, 24, 499-450. https://doi.org/10.5144/0256-4947.2004.119

[24] Abdulmughni, Y.A., et al. (2004) Thyroid Cancer in Yemen. Saudi Medical Journal, 25, 55-59.

[25] Al-Jaradi, M., et al. (2005) Prevalence of Differentiated Thyroid Cancer in 810 Cases of Surgically Treated Goiter in Yemen. Annals of Saudi Medicine, 25, 394-339.

[26] Al-Sharafi, B.A., et al. (2020) Thyroid Cancer among Patients with Thyroid Nodules in Yemen: A Three-Year Retrospective Study in a Tertiary Center and a Specialty Clinic. Thyroid Research, 13, Article No. 8. https://doi.org/10.1186/s13044-020-00082-x

[27] Burkan, N., Qubati, M., Qubati, S., et al. (2021) The Risk of Thyroid Carcinoma in Multinodular Goiter Compared to Solitary Thyroid Nodules: A Prospective Analysis of 207 Patients. Journal of Surgical Endocrinology, 3, 81-88. https://doi.org/10.36959/608/453

[28] Zamora, E.A., Khare, S. and Cassaro, S. (2020) Thyroid Nodule. StatPearls.

[29] Delbridge L (2006) Solitary Thyroid Nodule: Current Management. ANZ Journal of Surgery, 76, 381-386. https://doi.org/10.1111/j.1445-2197.2006.03727.x

[30] Boelaert, K., et al. (2006) Serum Thyrotropin Concentration as a Novel Predictor of Malignancy in Thyroid Nodules Investigated by Fine-Needle Aspiration. The Journal of Clinical Endocrinology \& Metabolism, 91, 4295-4301. https://doi.org/10.1210/jc.2006-0527

[31] Keh, S.M., et al. (2015) Incidence of Malignancy in Solitary Thyroid Nodules. The Journal of Laryngology \& Otology, 129, 677-681. https://doi.org/10.1017/S0022215115000882

[32] Kitahara, C.M. and Sosa, J.A. (2016) The Changing Incidence of Thyroid Cancer. Nature Reviews Endocrinology, 12, 646-653. https://doi.org/10.1038/nrendo.2016.110

[33] Sanabria, A., et al. (2018) Growing Incidence of Thyroid Carcinoma in Recent Years: Factors Underlying Overdiagnosis. Head \& Neck, 40, 855-866. https://doi.org/10.1002/hed.25029

[34] Muratli, A., et al. (2014) Diagnostic Efficacy and Importance of Fine-Needle Aspiration Cytology of Thyroid Nodules. Journal of Cytology, 31, 73-78. https://doi.org/10.4103/0970-9371.138666

[35] Cibas, E.S. and Ali, S.Z. (2009) The Bethesda System for Reporting Thyroid Cytopathology. American Journal of Clinical Pathology, 132, 658-665. https://doi.org/10.1309/AJCPPHLWMI3JV4LA

[36] Mondal, S.K., Sinha, S., Basak, B., Roy, D.N. and Sinha, S.K. (2013) The Bethesda System for Reporting Thyroid Fine Needle Aspirates: A Cytologic Study with Histologic Follow-Up. Journal of Cytology, 30, 94-99. https://doi.org/10.4103/0970-9371.112650

[37] Kuru, B., et al. (2009) Predictive Index for Carcinoma of Thyroid Nodules and Its Integration with Fine-Needle Aspiration Cytology. Head \& Neck. Journal for the Sciences and Specialties of the Head and Neck, 31, 856-866. https://doi.org/10.1002/hed.21049 
[38] Pinchot, S.N., Al-Wagih, H., Schaefer, S., Sippel, R. and Chen, H. (2009) Accuracy of Fine-Needle Aspiration Biopsy for Predicting Neoplasm or Carcinoma in Thyroid Nodules $4 \mathrm{~cm}$ or Larger. Archives of Surgery, 144, 649-655.

https://doi.org/10.1001/archsurg.2009.116

[39] Rosario, P.W., Penna, G.C. and Calsolari, M.R. (2014) Predictive Factors of Malignancy in Thyroid Nodules with Repeatedly Nondiagnostic Cytology (Bethesda Category I): Value of Ultrasonography. Hormone and Metabolic Research, 46, 294-298. https://doi.org/10.1055/s-0034-1367044

[40] Lima, P.C.M., et al. (2013) Risk Factors Associated with Benign and Malignant Thyroid Nodules in Autoimmune Thyroid Diseases. ISRN Endocrinology, 2013, Article ID: 673146. https://doi.org/10.1155/2013/673146

[41] Rahmani, N., et al. (2013) Clinical Management and Outcomes of Papillary, Follicular and Medullary Thyroid Cancer Surgery. Medicinski Glasnik, 10, 164-167.

[42] Kamran, S.C., et al. (2013) Thyroid Nodule Size and Prediction of Cancer. The Journal of Clinical Endocrinology \& Metabolism, 98, 564-570. https://doi.org/10.1210/jc.2012-2968

[43] Nam-Goong, I.S., Kim, H.Y., Gong, G., Lee, H.K., Hong, S.J., Kim, W.B. and Shong, Y.K. (2004) Ultrasonography-Guided Fine-Needle Aspiration of Thyroid Incidentaloma: Correlation with Pathological Findings. Clinical Endocrinology, 60, 21-28. https://doi.org/10.1046/j.1365-2265.2003.01912.x

[44] Cavallo, A., et al. (2017) Thyroid Nodule Size at Ultrasound as a Predictor of Malignancy and Final Pathologic Size. Thyroid, 27, 641-650.

https://doi.org/10.1089/thy.2016.0336

[45] Godazandeh, G., et al. (2016) Evaluation the Relationship between Thyroid nodule size with Malignancy and Accuracy of Fine Needle Aspiration Biopsy (FNAB). Acta Informatica Medica, 24, 347-350. https://doi.org/10.5455/aim.2016.24.347-350

[46] Valderrabano, P., Khazai, L., Thompson, Z.J., et al. (2018) Association of Tumor Size with Histologic and Clinical Outcomes among Patients with Cytologically Indeterminate Thyroid Nodules. JAMA Otolaryngology: Head \& Neck Surgery, 144, 788-795.

[47] Khadilkar, U.N. and Maji, P (2008) Histopathological Study of Solitary Nodules of Thyroid. Kathmandu University Medical Journal, 6, 486-490.

https://doi.org/10.3126/kumj.v6i4.1740

[48] Sclafani, A.P., Valdes, M. and Cho, H. (1993) Hashimoto's Thyroiditis and Carcinoma of the Thyroid: Optimal Management. Laryngoscope, 103, 845-849. https://doi.org/10.1288/00005537-199308000-00003

[49] Can, A.S. (2009) Cost-Effectiveness Comparison between Palpation- and Ultrasound-Guided Thyroid Fine-Needle Aspiration Biopsies. BMC Endocrine Disorders, 9, Article No. 14. https://doi.org/10.1186/1472-6823-9-14

[50] Cooper, D.S., Doherty, G.M., Haugen, B.R., Kloos, R.T., Lee, S.L., et al. (2009) Revised American Thyroid Association Management Guidelines for Patients with Thyroid Nodules and Differentiated Thyroid Cancer. Thyroid, 19, 1167-1214. https://doi.org/10.1089/thy.2009.0110

[51] Bagga, P.K. and Mahajan, N.C. (2010) Fine Needle Aspiration Cytology of Thyroid Swellings: How Useful and Accurate Is It? Indian Journal of Cancer, 47, 437-442. https://doi.org/10.4103/0019-509X.73564

[52] Haugen, B.R., Alexander, E.K., Bible, K.C., Doherty, G.M., Mandel, S.J., Nikiforov, Y.E., et al. (2015) 2015 American Thyroid Association Management Guidelines for Adult Patients with Thyroid Nodules and Differentiated Thyroid Cancer: The Ameri- 
can Thyroid Association Guidelines Task Force on Thyroid Nodules and Differentiated Thyroid Cancer. Thyroid, 26, 1-133. https://doi.org/10.1089/thy.2015.0020

[53] Wiltshire, J.J., Drake, T.M., Uttley, L. and Balasubramanian, S.P. (2016) Systematic Review of Trends in the Incidence Rates of Thyroid Cancer. Thyroid, 26, 1541-1552. https://doi.org/10.1089/thy.2016.0100

[54] Davies, L. and Welch, H.G. (2014) Current Thyroid Cancer Trends in the United States. JAMA Otolaryngology. Head \& Neck Surgery, 140, 317-322. https://doi.org/10.1001/jamaoto.2014.1

[55] Kuo, T.C., Wu, M.H., Chen, K.Y., Hsieh, M.S., Chen, A. and Chen, C.N. (2020) Ultrasonographic Features for Differentiating Follicular Thyroid Carcinoma and Follicular Adenoma. Asian Journal of Surgery, 43, 339-346. https://doi.org/10.1016/j.asjsur.2019.04.016

[56] Rago, T., et al. (2007) Combined Clinical, Thyroid Ultrasound and Cytological Features Help to Predict Thyroid Malignancy in Follicular and Hürthle Cell Thyroid Lesions: Results from a Series of 505 Consecutive Patients. Clinical Endocrinology, 66, 13-20. https://doi.org/10.1111/j.1365-2265.2006.02677.x

[57] Uyar, O., Cetin, B., Aksel, B., et al. (2017) Malignancy in Solitary Thyroid Nodules: Evaluation of Risk Factors. Oncology Research and Treatment, 40, 360-363. https://doi.org/10.1159/000464409

[58] Papini, E., et al. (2002) Risk of Malignancy in Nonpalpable Thyroid Nodules: Predictive Value of Ultrasound and Color-Doppler Features. The Journal of Clinical Endocrinology \& Metabolism, 87, 1941-1946. https://doi.org/10.1210/jcem.87.5.8504

[59] Edino, S.T., et al. (2010) Thyroid Cancers in Nodular Goiters in Kano, Nigeria. Nigerian Journal of Clinical Practice, 13, 298-300.

[60] Zhang, Y., Jiang, Q., Zhang, Y.X., Chen, J. and He, Z. (2015) Contrast-Enhanced Ultrasound in the Diagnosis of Solitary Thyroid Nodules. Journal of Cancer Research and Therapeutics, 11, 41-45. https://doi.org/10.4103/0973-1482.147382

[61] Desjardins, J.G., Khan, A.H., Montupet, P., et al. (1987) Management of Thyroid Nodules in Children: A 20-Year Experience. Journal of Pediatric Surgery, 22, 736-739. https://doi.org/10.1016/S0022-3468(87)80616-4

[62] Tafti, D. and Schultz, D. (2020) Thyroid Nodule Biopsy. StatPearls.

[63] Patnayak, R., et al. (2012) Seeking Help from Shadows. American Journal of Clinical Pathology, 137, 501-502. https://doi.org/10.1309/AJCPNJVEXYCKT78U

[64] Patnayak, R., Jena, A. and Bodagala, V. (2012) Better Cytological Evaluation of Thyroid Lesions Is Possible with Imageological Findings. Thyroid Research and Practice, 9, 107. https://doi.org/10.4103/0973-0354.99664

[65] Anderson, T.J.T., et al. (2014) Management of Nodules with Initially Nondiagnostic Results of Thyroid Fine-Needle Aspiration: Can We Avoid Repeat Biopsy? Radiology, 272, 777-784. https://doi.org/10.1148/radiol.14132134

[66] Arul, P. and Masilamani, S. (2015) A Correlative Study of Solitary Thyroid Nodules Using the Bethesda System for Reporting Thyroid Cytopathology. Journal of Cancer Research and Therapeutics, 11, 617-622. https://doi.org/10.4103/0973-1482.157302

[67] Wagana, L.N., et al. (2002) Management of Solitary Thyroid Nodules in Rural Africa. East African Medical Journal, 79, 584-587. https://doi.org/10.4314/eamj.v79i11.8803

[68] Calò, P.G., et al. (2017) Role of Prophylactic Central Neck Dissection in Clinically Node-Negative Differentiated Thyroid Cancer: Assessment of the Risk of Regional 
Recurrence. Updates in Surgery, 69, 241-248.

https://doi.org/10.1007/s13304-017-0438-8

[69] Chen, L., et al. (2018) Prophylactic Central Neck Dissection for Papillary Thyroid Carcinoma with Clinically Uninvolved Central Neck Lymph Nodes: A Systematic Review and Meta-Analysis. World Journal of Surgery, 42, 2846-2857.

https://doi.org/10.1007/s00268-018-4547-4 